\title{
Report of the Workshop on Status and Trends of Western North Atlantic Right Whales
}

\section{INTRODUCTORY ITEMS}

The meeting was held at the Northeast Fisheries Science Center (NEFSC), Woods Hole, Massachusetts, USA from 24-27 October 1999.

Dr John Boreman (Deputy Science Director of the NEFSC) welcomed participants to the NEFSC and noted the importance of the Workshop to the management of right whales by the US National Marine Fisheries Service.

Donovan welcomed the participants on behalf of the IWC and thanked them for coming to the meeting. He noted the great importance attached by both the Scientific Committee and the Commission to the status of the western North Atlantic right whale, particularly since the 1998 Workshop held in Cape Town (IWC, 2001), hereafter referred to as the Cape Town Workshop.

In 1998, an Intersessional Steering Group had been set up by the Scientific Committee to review ongoing work in relation to the status and trends of the North Atlantic right whale population, and to consider whether sufficient progress had been made to hold a workshop on this topic (IWC, 1999b). This was in response to recommendations made at the Cape Town Workshop.

At the 1999 Scientific Committee meeting (IWC, 2000a), discussion first centred around a recently published analysis of trends in the survival probability of North Atlantic right whales (Caswell et al., 1999). That analysis estimated a decrease in annual survival rate from 0.99 in 1980 to 0.94 in 1994 and an expected time to extinction of less than 191 years. An earlier version of the analysis had been submitted to the 1998 Cape Town Workshop.

The Committee had concluded that whilst it had some questions on the approach used, these did not alter the Committee's conclusion of 1998 that there are 'serious concerns over the status of the stock'. Those concerns were based on inter alia: the small size (300-350 animals) of the stock; an increase in calving interval from an average of 3.67 years in the 1980s to over 5 years in the 1990s; poor recent calf production; the possibility of an unusually high degree of female senescence (only $38 \%$ of females are reproductively active); and the level of anthropogenic mortality. Under these circumstances the Committee had strongly recommended that the Comprehensive Assessment of this stock should remain of high priority.

Clapham (Convenor) welcomed participants to the meeting, and thanked Sara Wetmore for the considerable assistance she had given in the organisation of the Workshop. Clapham reiterated the terms of reference for the Workshop given by the Scientific Committee (IWC, 1999c), that:

...the Comprehensive Assessment of the western North Atlantic right whale should be a priority topic... with its objectives being to establish the current status and dynamics of the population.

Bannister was elected Chairman. Clapham, Hammond and Taylor agreed to act as rapporteurs with assistance from Donovan and others where appropriate. Donovan, Clapham, Hammond and Bannister edited the final report.

A list of participants is given as Annex A.

\section{AGENDA}

The draft agenda developed by the Steering Group was adopted as shown in Annex B.

\section{REVIEW OF DOCUMENTS}

A list of documents considered by the Workshop is given in Annex C.

\section{REVIEW OF AVAILABLE DATA}

Hamilton summarised the available data from the North Atlantic Right Whale Catalogue (NARWC, curated at the New England Aquarium), which details any sighting of a right whale for which the animal was positively photo-identified. NARWC data include dates, times and locations of sightings, sex, age (in years) and age class of the individual, its reproductive history (if female), genotype information, behaviour and identifying characteristics. By July 1999, there were more than 14,000 photographically identified sightings of 396 individuals, 11 of which are known to be dead (an additional mortality of an identified animal occurred in October 1999). The earliest record is from 1935.

The five major areas of effort (Fig. 1) have been the southeastern USA (the only known calving ground), Massachusetts Bay/Cape Cod Bay, Great South Channel, the Bay of Fundy and Browns Bank/Roseway Basin (also referred to as the Scotian Shelf). The period of most consistent effort is from 1983 to date, with variability among areas. In particular, effort essentially ceased in the Great South Channel in 1990 and did not resume until 1998, and beginning in 1993, right whales abandoned Roseway Basin, resulting in a subsequent lack of effort in that area. There has been no systematic coding for photograph quality or individual distinctiveness in the NARWC. Although there are sightings for which photographic quality and distinctiveness make it impossible to establish individual identity in that case, it is unlikely that the population contains individuals with insufficient markings to be identifiable (i.e. are not uniquely marked).

Sightings probability through photo-identification is affected by the chances of encountering whales, selection of whales to be photographed, obtaining adequate photographs and matching to the existing catalogue. Variation in these processes can introduce heterogeneity in sightings probability, which primarily biases estimates of population size and to a lesser degree, estimates of survival rate (e.g. Hammond et al., 1990). Annual sighting histories of whales were constructed based on the composite result of all sampling throughout the year in all regions. The composite nature of the sampling should reduce the effects of heterogeneity somewhat by increasing overall sightings probability. However, heterogeneity in sightings probability has been identified through goodness-of-fit tests (SC/O99/RW5) for time dependent models. 
A Working Group established under Laake (Annex D) identified various sources of heterogeneity in sightings probability from each aspect of the photo-identification process. The mark-recapture models in SC/O99/RW2 and SC/O99/RW7 incorporate features such as sex, age or stage, and spatial/temporal distribution patterns to model heterogeneity in sightings probability. Those covariates are useful proxies for the sources of variation in the photo-identification process identified in Annex D.

Kenney summarised the North Atlantic Right Whale Database (NARWD, curated at the University of Rhode Island). This contains all sightings (approximately 15,000 sightings of from 1-40+ animals per sighting) of right whales, whether the animal was photographed or not; it also contains sightings of other species. Effort sources are either dedicated or opportunistic; information on the type and extent of effort is generally available for dedicated surveys, but there are gaps for some areas in some years. Although an SPUE-type analysis might be possible with these data, there is currently no consistent and standardised measure of effort that could be utilised in an identifications per unit effort analysis.

White summarised the genetic database, which is curated at McMaster University, Canada. For each individual, this includes sex, mitochondrial DNA haplotype, genotype at nine microsatellite loci and at four MHC loci. Comparisons of genotype and photo-identification data indicate a very low error rate in either. There are 253 identified individuals which have been biopsied; in addition, biopsies exist for 45 animals not matched to an individual in the NARWC because either no photographs (or inadequate photographs) were obtained at the time of sampling or the animal was a dead neonate or adult for which no individual identification was possible.

Additional available data on right whales include those on blubber thickness, contaminants, stable isotopes, fatty acids, tagging and entanglements; these are not included in the centralised databases described above, but can be linked to

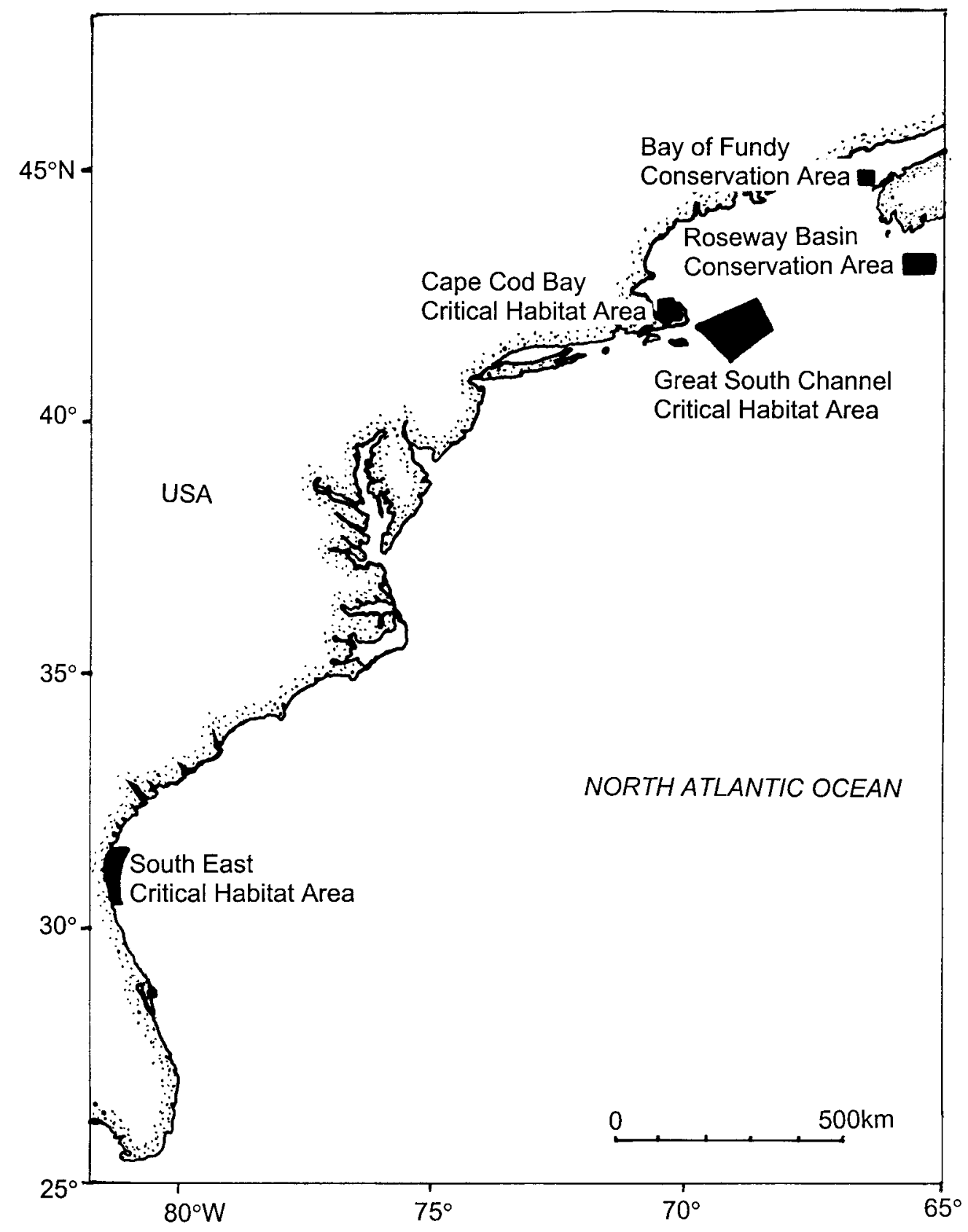

Fig. 1. Eastern North Atlantic. Major areas of effort. 
individuals in the NARWC. There is also information on dead right whales, often including necropsy data. In addition, identification photographs can be used for the purpose of health assessment, for example from scars, fungal-like growths or lesions (Hamilton et al., 1995).

All the data noted above are accessible through the North Atlantic Right Whale Consortium, which has established formal protocols for data access. Further information is available from Kraus (address in Annex A).

\subsection{Recommendations}

The Workshop recommends that goodness-of-fit tests be conducted for models developed in SC/O99/RW2 and SC/O99/RW7, to evaluate whether additional heterogeneity remains. Further theoretical development for the goodness-of-fit test may be required for the model in $\mathrm{SC}$ O99/RW7. If there is further evidence of heterogeneity, covariates should be used that describe whale distinctiveness and photographic quality through time. This will require retrospective inspection of the catalogue and will require a major effort.

The Workshop also recommends that from now on, the quality and distinctiveness codes identified during the Cape Town Workshop (IWC, 2001) should be used to classify photographs in the existing catalogue. Any changes (e.g. reassignments of animals, retrospective assignments of identifications or sex) should be documented within the database.

The Workshop noted that Burnell had developed a semi-automated matching process for southern right whales (Burnell et al., 2001), and recommends that its applicability to northern right whales should be investigated.

\section{REVIEW OF AVAILABLE MODELS}

Previously, the Scientific Committee had reviewed the analysis of Caswell et al. (1999) on trends in the survival probability of the North Atlantic population (IWC, 2000b). Questions were raised with regard to the statistical approach and the certainty that could be attached to the results. The Committee had recommended that further work be conducted, including the development of stage-structured models and those that attempted to incorporate additional spatial heterogeneity. That work has now been undertaken, and under this item the Workshop discussed the aims, data requirements, assumptions and limitations of each model available. An overview is given in Table 1.

Fujiwara reported on a model (SC/O99/RW7) that examined the effects of heterogeneity due to sex and developmental stage on estimates of survival and transition probabilities. The model classified individuals by sex and as calves, immature, mature (at least nine years old, or females known to have reproduced), and for females as mature with calf. Transition probabilities among stages were estimated using multi-stage mark-recapture methodology with maximum likelihood, and models were compared using the Akaike Information Criteria, AIC (Akaike, 1973). Animals of unknown sex or stage contributed to the likelihood function according to weighted averages of the likelihoods for males and females (assuming a 50:50 sex ratio) or for juveniles and mature animals (assuming proportions derived from a time-invariant model). Transition probabilities for each stage were allowed to vary as polychotomous logistic functions of time. Stage-specific sightings probabilities were allowed to vary as a function of time and/or of sampling effort. The best description of sightings probability according to AIC was obtained, allowing all transition probabilities to vary as logistic functions of time. Then the best transition model was selected using the best sightings model.

The transition model was turned into a two-sex female-dominant population projection matrix by noting that the transition from mature to female with calf produces a new calf. The resulting model was analysed using standard projection matrix methodology to compute population growth rates, stable stage distributions, and sensitivity and elasticity of growth rate. Absorbing Markov chain theory

Table 1

Comparison of available models for estimation of survival $(\phi)$, sighting probability $(p)$, inter-birth interval and finite population growth rate $(\lambda)$. Each method relies on photo-identification data and the mark-recapture models all require the assumptions summarised in Hammond (1986) with appropriate modifications relating to homogeneity of survival and sighting probabilities. $\mathrm{A}=\mathrm{Crude} \phi, \mathrm{B}=\mathrm{Stage}-\mathrm{specific} \phi ; \mathrm{C}=\mathrm{Sex}$ specific $\phi ; \mathrm{D}=\mathrm{Annual} p$; $\mathrm{E}=$ Stage $p ; \mathrm{F}=\mathrm{Sex} p ; \mathrm{G}=$ Spatial $p$ and $\phi ; \mathrm{H}=$ Inter-birth interval; NA=North Atlantic; $\mathrm{SA}=$ South Atlantic.

\begin{tabular}{|c|c|c|c|c|c|c|c|c|c|c|c|}
\hline \multirow[b]{2}{*}{ Model } & \multicolumn{10}{|c|}{ Parameters } & \multirow[b]{2}{*}{ Comments } \\
\hline & Population & A & B & $\mathrm{C}$ & $\mathrm{D}$ & $\mathrm{E}$ & $\mathrm{F}$ & G & $\mathrm{H}$ & $\lambda$ & \\
\hline $\begin{array}{l}\text { Mark-recapture: } \\
\text { 2-sex multi-stage transition } \\
\text { model (SC/O99/RW7) }\end{array}$ & NA only & & $\mathrm{x}$ & $\mathrm{x}$ & $\mathrm{x}$ & $\mathrm{x}$ & $\mathrm{x}$ & & $\mathrm{x}$ & $\mathrm{x}$ & $\begin{array}{l}\text { Uses translated exponential distribution for inter-birth interval; all } \\
\text { calving intervals exceed } 2 \text { years. }\end{array}$ \\
\hline $\begin{array}{l}\text { Mark-recapture: } \\
\text { 3-stage model, adult females } \\
\text { only (SC/O99/RW5) }\end{array}$ & NA and SA & & $\mathrm{x}$ & $\mathrm{x}$ & $\mathrm{x}$ & $\mathrm{x}$ & $\mathrm{x}$ & & $\mathrm{x}$ & & $\begin{array}{l}\text { Uses translated exponential distribution for inter-birth interval; all } \\
\text { calving intervals exceed } 2 \text { years; used only sightings of females with } \\
\text { calves. }\end{array}$ \\
\hline $\begin{array}{l}\text { Mark-recapture: } \\
\text { Crude survival, sighting } \\
\text { probability function of } \\
\text { spatial location } \\
\text { (Caswell et al., 1999) }\end{array}$ & NA & $\mathrm{x}$ & & & $\mathrm{x}$ & & & $\mathrm{x}$ & & $\mathrm{x}$ & $\begin{array}{l}\text { Survival probability function of time, sighting probability a function } \\
\text { of tendency of individual to be seen offshore. Population growth rate } \\
\text { calculated from crude survival and birth-intervals reported by Kraus } \\
\text { et al. }(2001) \text {. }\end{array}$ \\
\hline $\begin{array}{l}\text { Mark-recapture: } \\
\text { Inter-birth interval model } \\
(\mathrm{SC} / \mathrm{O} 99 / \mathrm{RW} 1)\end{array}$ & $\mathrm{NA}$ and SA & & $\mathrm{x}$ & $\mathrm{x}$ & $\mathrm{x}$ & $\mathrm{x}$ & $\mathrm{x}$ & & $\mathrm{x}$ & $\mathrm{x}$ & $\begin{array}{l}\text { Inter-birth interval proportions through age } 5 \text { are free parameters } \\
\text { with an exponential decline beyond age } 5 \text {; used only sightings of } \\
\text { females with calves in southeast US, Bay of Fundy, and } \\
\text { Massachusetts Bay. }\end{array}$ \\
\hline $\begin{array}{l}\text { Mark-recapture: } \\
\text { Cormack-Jolly-Seber model } \\
\text { with spatial component } \\
\text { (SC/O99/RW2) }\end{array}$ & NA only & & $\mathrm{x}$ & & $\mathrm{x}$ & & & $\mathrm{x}$ & & & $\begin{array}{l}\text { Spatial heterogeneity incorporated by clustering whales of similar } \\
\text { spatial sighting distribution and using the clusters as strata in the } \\
\text { mark-recapture analysis. }\end{array}$ \\
\hline $\begin{array}{l}\text { Back calculation } \\
(\mathrm{SC} / \mathrm{O} 99 / \mathrm{RW} 3)\end{array}$ & NA only & $\mathrm{x}$ & & & & & & & & & $\begin{array}{l}\text { Any individual not observed for } 6 \text { years is presumed dead; some } \\
\text { sighting histories removed to accommodate reduction in effort in } \\
\text { offshore regions. }\end{array}$ \\
\hline
\end{tabular}


was used to compute life expectancy, net reproductive rate, generation time, and expected number of lifetime reproductive episodes. The model was then transformed into a multitype branching process to compute extinction probabilities under demographic stochasticity and the probability distribution of time to extinction.

In discussion, a question was raised regarding whether stage-structured models were inferior to age-classified models because of the greater degree of precision associated with the latter. It was noted that a comparison of stage- and age-classified models for a single data set, on killer whales, showed broad agreement between them (Brault and Caswell, 1993); however, it should be borne in mind that age-structured models tend to be over-parameterised. In any stage-structured model there will inevitably be variability amongst animals within stages and in age-classified models there will be variability (e.g. reproductive versus non-reproductive) among animals within age classes. Potentially significant bias could be investigated by sensitivity analyses. Variability among animals within stages will be reflected in the precision of parameter estimates. More important is misclassification of animals into stages, which may cause errors in estimation or parameterisation.

Brault summarised the results of a recent Workshop held at the Woods Hole Oceanographic Institution, WHOI, (SC/O99/RW5), which examined the performance of different models. Recommendations of the WHOI Workshop for future work included: examination of the potential effect of data post-stratification on model estimation; use of within-year information to attempt classification of individuals by capturability; and simulation of capture histories to investigate the impact of heterogeneity on existence and detectability of a decline in survival. The model developed by Cooke et al. (2001) for analysis of southern right whale data was applied to sightings data of females with calves in the North Atlantic; its high sensitivity to annual fluctuations in number of births subsequently led to modifications of the model and its conclusions as presented in SC/O99/RW1. A model for mature females only was developed by Fujiwara to compare the demography of North Atlantic and southern right whales. Preliminary results show lower survival of females with calves in the North Atlantic than in the Southern Hemisphere, as well as a higher interbirth interval. Overall, alternative analyses to that of SC/O99/RW7 tend to support the finding of a decrease in survival (see Item 6.5).

In discussion, a number of clarifications were made. The analysis using program MARK introduced a stage for unknown sex; the Fujiwara model allocated unknown sex animals to sex in a 1:1 ratio. All models considered in SC/O99/RW5 accounted for heterogeneity in capture probabilities over time. Biological differences among individuals were not modelled except in groups in the stage-structured models. No models used data stratified by area but a model for the Bay of Fundy only was run. It was noted that this model would not necessarily reduce spatial heterogeneity because of the wide range of capture histories observed in that area, and could actually increase it. The best-fitting model in Caswell et al. (1999) did include the 'offshore indicator' variable. It was noted that for spatial heterogeneity, the most important aspect was whether there were trends over time because this may lead to a trend in estimates of survival rate.

SC/O99/RW1 provided a comparative analysis of the demography of the calving female components of the South Atlantic and North Atlantic right whale populations, using a model originally developed for analysis of the southern right whale photo-identification data. The model provides estimates of the distribution of calving intervals (implicitly corrected for missed calvings) the mean age at first calving, the survival rate of reproductive females and the rate of population change. The sightings of females with calves by year were grouped into two areas (Bay of Fundy/Massachusetts Bay and the southeastern USA calving ground) and the model assumed homogeneity of sighting probabilities within each area in each year. Since the model makes use only of identifications of females with calves, it is not optimal for the northern right whale for which these records constitute less than $10 \%$ of the total data set.

SC/O99/RW3 presented a preliminary analysis of a study to examine the impact of heterogeneity and presumed mortality on the estimation of population parameters. The study concluded that the apparent increase in mortality rate in recent years was largely attributable to heterogeneity combined with spatial sampling bias.

In discussion, questions were raised relating to the use of data on presumed mortalities and on the potential use of effort data to aid the assignment of animals to inshore or offshore categories. The Workshop agreed that it was inappropriate to use presumed mortalities when estimating survival. However, it noted that the examination of observed intervals between sightings might be useful in assessing the validity of model predictions and investigating those individual animals that had longer than predicted intervals between sightings.

SC/O99/RW2 investigated the influence of spatial heterogeneity among areas on estimated survival rates. Sightings data for individually identified right whales between 1980 and 1997 were examined by cluster analysis to form groups of whales with similar spatial distributions, using the proportion of years out of the total when animals were seen in each of the five main habitat areas. The following clusters were used:

(a) Massachusetts Bay/southeastern USA/Bay of Fundy (MASS/SEUS/BOF);

(b) Scotian Shelf/Great South Channel (SS/GSC);

(c) Bay of Fundy (BOF);

(d) Bay of Fundy/Scotian Shelf (BOF/SS).

Mark-recapture analysis was performed on the grouped sighting histories with the program MARK, using a general form of the Cormack-Jolly-Seber model. Three different sighting probability models were examined with sightings probability varying by: (1) year; (2) group; and (3) group and year. Six different survival probability models were examined for non-calf survival: (1) survival constant; (2) varying by year; (3) varying through time by a logistic model as in Caswell et al. (1999); (4) varying by group but constant across years; (5) varying by year and by group; and (6) varying through time by a different logistic model for each group. Calf survival was initially assumed to be constant. These 18 possible models were compared using AIC. Once the best models for sightings probability and survival had been selected, year-dependent and logistic trend in calf survival were compared to constant calf survival.

In general discussion, two features emerged that might be implied from the observed data but may not be captured in the models. The first was the suggestion that sightings probabilities for females in the years following a calf year had decreased with an associated increase in calving interval. Assuming a typical reproductive cycle might lead to an increase in 'missing' whales. The second was that estimated calving intervals appeared to be lower than 
observed ones. This might be a result of sampling effort tending to focus on 'Surface Active Groups', which comprised sexually active animals. The Workshop noted that the Fujiwara model (SC/O99/RW7) estimated capture probabilities and survival rates for different reproductive classes, and that an important feature of the Wade and Clapham model (SC/099/RW2) was that it addressed spatial aspects without discarding data.

After the presentation of the individual models, Taylor gave a brief presentation on the aim of models in assessing the status and trends of endangered populations and the use of simulation models to test model assumptions and parameter estimates. She noted that the models discussed at the Workshop were useful in estimating trends and population parameters, but that they did not explicitly seek to identify sources of risk in an endangered population. She further cautioned that models designed for use on large, potentially harvestable populations (such as minke whales) are often inappropriate for examining the dynamics and trends of small, critically endangered populations such as right whales where demographic stochasticity is often greatly magnified. She suggested two stages in modelling: (1) models to evaluate levels and trends in risk and (2), if increased risk is plausible, models that try to identify the source of increased risk and that are structured to rank needed research and management options. She noted that the models discussed in this Workshop have been generally at the first stage of risk identification. Given that increased risk is plausible and probable, the second stage should now proceed. The Workshop noted that the analyses of Caswell et al. (1999) and SC/O99/RW7 do incorporate their parameter estimates into demographic models and permit some quantification of risk and include demographic stochasticity. The value of incorporating genetic data into future models is discussed under Item 6.1.1 and in Annex E.

Taylor suggested a method to proceed that began with listing plausible sources for observing increased risk which include: re-distribution (poor conditions leading to a reduction in both calf production and capture rate of adult females), ship strikes, entanglement and direct mortality through poor environmental conditions. Models can then consider various hypotheses and evaluate their plausibility according to the compatibility of the model results with the various types of data (photographic and genetic) and the distribution of risk factors such as fishing gear and shipping traffic. The results could be used to eliminate hypotheses, strengthen conclusions about status and trends, prioritise research and guide management decisions. The difficulty in setting plausible bounds on simulation models used to assess hypotheses or model assumptions was acknowledged but it was noted that such problems had been successfully addressed previously within the IWC by assembling a group to recommend suitable bounds.

\section{OVERVIEW OF EXISTING KNOWLEDGE OF POPULATION PARAMETERS}

\subsection{Stock and sub-stock structure}

Under this Item, the Workshop considered only information additional to that presented at the Cape Town Workshop (IWC, 2001).

White summarised SC/O99/RW6 and other recent genetics papers on this population (Malik et al., 1999; 2000; Waldick et al., 1999). Sightings data indicate the existence of two subsets of mature females, both of which are observed in the southeastern USA but only one of which is resighted in the Bay of Fundy in summer. Mitochondrial DNA
(mtDNA) data suggest that these two groups show significant differences in haplotype/allele frequencies, a phenomenon which is probably due to maternally directed philopatry. Current work focuses on: population substructure; the mating system; effective population size; size of population since exploitation; census size of the population; paternity/maternity analyses of individuals of unknown relatedness; and MHC (Major Histocompatibility Complex) variation relative to reproductive success. There are five mtDNA haplotypes in the population, with greatly varying frequency. Summary measures of allelic frequency suggest a bimodal distribution in a subset of Bay of Fundy animals which is not found in the 'non-Fundy' group (i.e. those animals not photographically identified in the Bay of Fundy). Simulations suggest that there is not random mating within the population, and that two mating areas may exist with a somewhat different population composition. Pedigree analysis suggests that the population contains some individuals that have yet to be sampled. An investigation of paternity suggests that approximately $85 \%$ of calves have different fathers. This is consistent with a mating system dominated by sperm competition but inconsistent with one dominated by a few males.

A question was raised regarding whether the 'missing' animals in the population could be accounted for by photo-identified animals that had yet to be biopsy sampled. White responded that mathematical analyses suggested that the population was somewhat larger than is assumed, even when non-biopsied individuals were accounted for. It was suggested that a breakdown of mtDNA data by sex might show immigration of males from other areas. The Workshop noted, however, that a certain level of discovery of 'new' animals is to be expected in any population. It also agreed that it is not possible to assess from the genetic data whether the apparent increase in mean calving intervals is due to senescence. Three historic specimens from the eastern North Atlantic (see Rosenbaum et al., 2000) had been found to be of the most common haplotype in the current western population, as was the individual observed recently in Arctic Norway (see below). However, the different exploitation histories and recovery (or lack thereof) suggest that for present management purposes (as opposed to evolutionary/ecological timescales), the two populations be considered discrete.

Concerns have been raised over the genetic diversity of North Atlantic right whales (Schaeff et al., 1997). Low genetic diversity can lead to a lowering of population fitness via the expression of deleterious alleles or the reduction of heterozygosity at loci such as MHC, which confers the ability to respond to disease. However, low diversity does not always indicate an unhealthy population. For example, several apparently healthy populations of cetaceans, such as sperm whales and pilot whales in all ocean basins, have even lower genetic diversity than observed for North Atlantic right whales. Comparing levels of genetic diversity across species may provide insight about differences that exist between species, but it is not possible to attribute hypothetical changes in gene diversity in one population from the level of genetic variation in another (Rosenbaum et al., 2000). The likelihood of a population expressing deleterious alleles depends on the number of such alleles remaining in the population, which itself depends on population history. Populations reduced to very low levels (typically fewer than 50 effective individuals) very rapidly lose genetic diversity without sufficient time for selection to purge deleterious alleles. On the other hand, populations that remain at low levels for long periods of time lose diversity 
and the potential for selection to purge deleterious alleles. Loss of allelic diversity can also result in the loss of beneficial alleles, such as MHC loci, which cannot be easily restored in small populations because low population size can support only low genetic diversity.

Several lines of research may help resolve whether reduction in fitness is likely, including research on MHC genotyping to see whether MHC loci are randomly transmitted. The Workshop concurred with the conclusions of the Cape Town Workshop that low genetic variation in North Atlantic right whales can best be interpreted through an analysis of historical versus extant samples and encourages further work along these lines. The Workshop also encourages further research examining whether a population bottleneck is likely. SC/O99/RW6 had found no heterozygote excess that would suggest a bottleneck in the last 150 years (using the analytical program 'Bottleneck'). However, the Workshop noted that the evolution of microsatellites is only partially understood. Further examination of mutational processes is desirable since this will improve interpretation of genetic data with respect to the plausibility of bottlenecks.

There was discussion of how genetic data should be incorporated into modelling exercises. The Workshop recognised that appropriate methods need to be developed. Analysts should consider the use of genetic data both for individual-based models and for group-based analyses, for example to investigate survival of individuals by mtDNA haplotype (see recommendation below).

Hamilton summarised sighting data relevant to population structure. Of 396 individuals identified, 25 have never been seen in any inshore habitat, and 117 were never seen offshore. In addition, 11 of 95 known mothers have never been observed in the only known calving ground in the southeastern USA; it is not clear whether this indicates the existence of a second calving area, or simply missed animals in the southeast.

Marx briefly summarised sightings of right whales in the eastern North Atlantic since 1960. Of particular interest in this regard was the sighting of a right whale in a Norwegian fjord in September 1999 that had been seen off Cape Cod in May 1999 (Øien and Marx, pers. comm.). Since 1960, there have been eight confirmed sightings (11 animals) in the eastern North Atlantic.

Rosenbaum et al. (2000) summarises ongoing genetic work on the question of the separation of eastern and western North Atlantic right whales.

\subsubsection{Recommendations (and see Item 8)}

The Workshop noted a number of important considerations with respect to analyses of the genetics data and their incorporation into population models. It strongly recommends that a Workshop on Right Whale Genetics be held in October 2000. Participants should include demographic modellers (see Item 7.2.1), cetacean biologists, genetics modellers and geneticists to: (1) explore a range of population genetic analytical techniques; (2) develop analytical techniques to estimate model parameters specific to right whale conservation models; and (3) identify the best approaches for future genetic research in terms of needed sampling, potential additional markers and development of future analytical techniques. Further details and rationale for this Workshop are given in Annex E.

The Workshop identified a number of ongoing genetic analyses that should ideally be completed before the
Genetics Workshop takes place. It recommends that this work continues expeditiously:

(1) complete multi-locus genotypes to discriminate between individuals and determine paternity for all available biopsy samples;

(2) complete genotyping of MHC loci for direct testing of whether right whales may be genetically compromised, in order to examine possible effects on reproductive success and resistance to disease.

It also recommends continued analysis of historical specimens to examine questions of population structure, and of early exploitation levels of genetic variation (especially at MHC loci) to test the hypothesis that reduced variation has a negative impact on reproduction. Samples have been obtained from the western North Atlantic $16^{\text {th }}$ century Basque right and bowhead whale fishery in Red Bay, Labrador, Canada. The right whale samples should be examined, together with any other historical samples that can be obtained. It is essential that published methodological safeguards to eliminate false positives associated with sample handling and laboratory data collection of historical samples are adhered to.

The Workshop also reviewed the following recommendations for genetic work made at the Cape Town Workshop (IWC, 2001).

(1) Reduction of known bias from regional sampling in July-October feeding habitats and completion of the archive of western North Atlantic.

Over the last two years, genetic sampling has continued annually from July to September in the Bay of Fundy. This does not represent a separate research effort but is carried out as part of vessel photo-identification surveys. There has been minimal sampling effort in Cape Cod Bay in winter and spring ( $\sim 3$ days per season). There has been virtually no sampling effort in the southeastern USA calving ground or in the Great South Channel because of a lack of funding.

The Workshop recommends that the current programme continue and be expanded. In particular, high priority should be given to obtaining samples from the calving ground, especially from females who do not take their calves to the Bay of Fundy.

(2) Examination of available information on mtDNA haplotypes, microsatellite and MHC genetic profiles with respect to habitat use, resighting probabilities, scarring patterns, and reproductive success.

The Workshop recommends that this work be undertaken.

(3) Transfer of samples under CITES regulations.

The Workshop noted that whilst not confined to samples for genetic analysis, transfer of samples under CITES regulations is still very difficult and can constitute a major impediment to research on critically endangered species such as northern right whales. It repeats the Cape Town Workshop recommendation that IWC member nations be strongly urged to facilitate the transfer of such samples, and that the IWC Secretariat approach the CITES Secretariat to consider expediting permits for bona fide institutions conducting conservation-related research on endangered species. 


\subsection{Population size}

Hamilton summarised estimates of population size from NARWC data. The rate of discovery of newly identified individuals reached an asymptote in 1982; relatively few new (non-calf) whales have been added in recent years.

The Workshop agreed that there were at least 263 animals alive (of which 56 were known to be mature females) in 1996. This is based on an examination of the NARWC and represents the number of identified animals seen in 1996 plus any animals that were seen both before and after 1996. It is thus a minimum direct count and not an estimate.

The mark-recapture analyses discussed at this meeting were designed to estimate survival rates, not abundance. It is more difficult to reliably estimate population size using mark-recapture data (e.g. see Buckland, 1990), as this requires calculation of the number of animals not seen in the sample. A number of estimates using mark-recapture techniques or involving various assumptions about presumed mortality of individuals are discussed in Annex F. It was agreed that estimation of current population size or trends in population size using those techniques is unlikely to provide reliable information on the status of this stock. Despite these caveats it was agreed that the results given in Annex F suggest that the overall abundance in 1996 is unlikely to have been considerably greater than 263 . A total of 338 known individuals was observed between 1988 and 1997.

The appropriateness of a population estimate depends on the use to which it is to be put. The Workshop agreed that in response to general queries it is reasonable to state that the current population size of the western North Atlantic right whale population is probably around 300 animals $( \pm 10 \%)$.

Unlike North Atlantic right whales, a number of other whale populations have apparently recovered from very low observed abundance (e.g. Southern Hemisphere right whales, eastern North Pacific gray whales, some Southern Hemisphere humpback whales). However, data to reliably estimate minimum historic abundance are invariably incomplete. North Atlantic right whales, like Southern Hemisphere humpback and right whale populations, may have gone through a genetic bottleneck. Since North Atlantic right whale numbers had not increased as in the Southern Hemisphere, there is the possibility of the occurrence of the 'Allee effect,' where population growth rate declines at low population size. Whether or not this is the case is cannot be evaluated with the available data. White noted that analyses reported in SC/O99/RW6 suggested that North Atlantic right whales may have been at a low level for hundreds of years and that investigations into the possibility of such an effect were continuing.

\subsection{Age composition}

Hamilton summarised the available data on age composition in the NARWC. There are records of 385 individuals (157 males, 153 females and 75 individuals of unknown sex). There are 69 known juveniles (less than nine years old), 298 adults and 18 of unknown age; in total, 11 individuals are known to have died, and 87 have not been sighted for six years or more (in certain analyses such animals are presumed dead, although as noted under Item 6.5 this is not a reliable means of estimating mortality). He noted that the proportion of juveniles in the population has dropped from $44 \%$ in 1990 to $23 \%$ in 1998 . This decline is not unexpected in a longitudinal study, although it is perhaps somewhat surprising given the high effort on the calving grounds and the fact that many calves would therefore be expected to be recruited into the NARWC population. It was noted that the figures given presumed that all animals included in the total were alive but had not all been sighted in the year (1998) for which calculations were undertaken.

\subsection{Reproduction}

Kraus et al. (2001) present the most recent analysis of reproduction in this population. Two measures of reproduction, Gross Annual Reproductive Rate (GARR) and Calves per Mature Female per Year (CMFY), were estimated, giving mean values of $0.049 / 0.043$ for GARR (depending on methodology) and 0.25 for CMFY. Interbirth intervals have increased from 3.67 years in 1992 to 5.8 years in 1998, and this does not appear to be an artefact of sightings effort. However, the analysis is contingent upon a number of assumptions regarding the probability of unobserved calving. It is also possible that some females may have given birth to calves that died prior to the mother being observed.

The results of the interbirth interval model given in SC/O99/RW1 were largely consistent with a conclusion of increasing intervals in recent years. A statistically significant increase (from 3.28 years in the 1980 s to 4.44 years in the 1990s) of estimated mean calving interval was obtained. The distribution of calving intervals indicates a shift from 3-year intervals in the 1980s towards 5+ year intervals in the 1990s, with the proportion of 4-year intervals little changed. The data are thus consistent with the hypothesis of an increased pre- or neonatal mortality in the 1990s, on the assumption that pre- or neonatal mortality tends to be followed by a 2-year interval whereas successful weaning tends to involve a 3-year interval following birth.

The Workshop agreed that calving intervals had indeed increased. It was not possible to assess whether this was due to lengthened intervals between births or to loss of an unrecorded neonate in the years between observed births. It is important to note that this analysis does not include the many mature females that have calved only once or not at all; thus, actual intervals are likely to be even greater than calculated. The Workshop noted that the question of whether this could be due to sampling bias, notably in offshore areas which were either abandoned by whales (Roseway Basin) or the subject of diminished effort (Great South Channel) during the period in which intervals had apparently increased, requires further investigation.

Calving interval information alone does not provide an estimate of the average reproductive rate of the entire mature female population, because of the possibility that some females are not reproductively active (Brown et al., 1994 and as alluded to under Item 6.1). Therefore the Workshop considered (i) direct estimates of the reproductive rate of the mature female population; and (ii) estimates of the proportion of mature females that are reproductive in the sense of having calved at least once.

Table 2 presents calf production by year in the 1990s from the animals known to be at least nine years old (and thus assumed to be mature) and which are presumed female; the latter was estimated as the known females plus half the animals of unknown sex. Support for an approximately 50:50 ratio among the unknown sex animals is given in SC/O99/RW7. The average annual calf production rate per mature female is 0.13 but substantial annual variation is observed.

Thus in 1996, there were 94 presumed live, known/presumed females known to be at least nine years old. Of these, 66 had been observed to calve at least once. This gives a conservative (due to missed calvings and some females reaching maturity after nine years of age) estimate of 
$70 \%$ for the proportion of mature females that are reproductively active. Using the direct estimate of apparent mean calving interval in the 1990s of 4.6 years (Kraus et al., 2001), which is very similar to the statistically 'corrected' estimate of 4.4 years (SC/O99/RW1), the implied average reproductive rate for mature females is $0.7 / 4.6=15 \%$, which is within the range shown in Table 2.

Table 2

Right whale calf production (for explanation see text). Adults presumed alive

Year Female (F) Unknown (U) F+0.5U No. calved Percent calves

\begin{tabular}{lllrrr}
\hline 1990 & 57 & 18 & 66 & 11 & 16.67 \\
1991 & 60 & 20 & 70 & 16 & 22.86 \\
1992 & 62 & 20 & 72 & 10 & 13.89 \\
1993 & 69 & 20 & 79 & 5 & 6.33 \\
1994 & 72 & 18 & 81 & 6 & 7.41 \\
1995 & 76 & 18 & 85 & 6 & 7.06 \\
1996 & 85 & 18 & 94 & 19 & 20.21 \\
1997 & 87 & 18 & 96 & 18 & 18.75 \\
1998 & 90 & 18 & 99 & 5 & 5.05 \\
Total & & & 742 & 96 & 12.94 \\
\hline
\end{tabular}

It is not possible to provide comparable estimates of average reproductive rate for the 1980s because animals need a sufficiently long sighting history to be determined to be at least nine years of age. However, in view of the increase in mean calving intervals in the 1990s relative to the 1980s, the Workshop agreed that it is very likely that the average reproductive rate was lower in the 1990s. It also noted with concern that the estimate of average reproductive rate was less than half of that obtained for the southern Atlantic populations (Best et al., 2001; Cooke et al., 2001). Given that in the 1990s most North Atlantic right whale calves were seen on the calving grounds, as in the Southern Hemisphere, the estimates for the two hemispheres are directly comparable.

Several possible explanations for the increased interbirth intervals in multiparous females were discussed. One proposed mechanism involved a decreasing food supply. Moore noted that the preliminary results of acoustic profiling for blubber thickness (SC/O99/RW4) suggest that northern right whales have significantly thinner blubber than Southern Hemisphere animals. However, the data have not been normalised inter alia for length and analysed sample sizes are small. Some participants believed that this was consistent with a hypothesis that food limitation might be responsible for the increase. They also referred to a purported correlation between reproductive rate and climatological changes that potentially affected the abundance and distribution of prey patches. Others believed that since Calanus is the most common zooplankton in the North Atlantic and that present right whale abundance is greatly below historic levels, the proposal that food limitation was the major factor seemed questionable.

Other ideas considered included the possibilities that:

(a) observed increasing frequencies of skin lesions may be indicative of poor health that could compromise reproduction;

(b) there is an unstable age structure, which includes an increasing number of reproductively senescent animals (although senescence has not been reported for baleen whales - e.g. see review in Lockyer, 1984 - and has rarely been documented in mammals, this may reflect lack of effort rather than lack of occurrence).
The Workshop agreed that the available data do not allow the identification of a cause for the increase in interbirth interval. It noted that it might well be the result of a combination of factors.

The Workshop noted that knowledge of length and (by possible inference) age is important for demographic analyses, including longitudinal studies of growth rate and of reproduction. Given that the technology exists to accurately measure individuals (e.g. Gordon, 1990; Best and Rüther, 1992), it recommends that this work be conducted on right whales, preferably in the form of an annual survey.

\subsection{Survivorship}

Caswell and Fujiwara presented stage-specific survival and sightings probability for the best fitting model from SC/O99/RW7. The most dramatic result was the trend in the estimated survival of females with a calf that had fallen from about 0.95 to about 0.65 from 1980 to 1995 . There were also decreases over time in the estimated survival of immature females and mature males. The capture probability for females with a calf was estimated to be constant but to have increased over time in all other stages, reflecting an increase in effort.

Questions were raised about the high constant capture probability of females with a calf; constant capture probability was neither supported by the data nor by results from Cooke's model (SC/O99/RW1). Fujiwara responded that choosing lower constant capture probabilities for this stage had little effect on estimates of survival rate and that if capture probability had increased over time, the downward trend in survival rate would be even steeper. However, he noted that this might be more important with respect to estimates of birth interval. Although a time trend in birth interval was not selected in the best model fit, he noted that this was not the most appropriate model structure to investigate this factor. He commented that the model in which all parameters are time dependent also shows a declining survival rate in females with a calf but noted that this has too many parameters to be useful. Caswell noted that the estimated constant capture probability had a wide confidence interval and that this aspect was being investigated further.

There was some discussion about the desirability or otherwise of modelling trends over time in survival rate when the lower estimates in recent years may be the result of chance events in one or more years rather than a smooth trend. Caswell noted that the fully time-dependent models in Caswell et al. (1999) and SC/O99/RW2 did not fit as well as modelling trends over time and believed that in principle it was better to fit a trend and investigate what might be causing that trend than to focus on particular events. Others believed that it was important to investigate particular atypical events (such as the high mortality in 1992); inspection of residuals around a trend was one way to do this. The Workshop agreed that modelling most parameters as trends but allowing survival of females with a calf to vary over time would be a useful exercise.

It was noted that in the absence of independent information, estimates of survival are always confounded with any emigration. The possibility that spatial structure in the population and sampling had resulted in animals becoming unavailable for sampling rather than dying could not be completely ruled out, but the model used in SC/O99/RW2 that did incorporate spatial structure also showed an overall decline in survival rate. 
In $\mathrm{SC} / 099 / \mathrm{RW} 1$, the model incorporating a trend in survival over time had the best AIC. The estimate of trend was negative but not precise. This was not surprising because the model only used a subset of the data (those for reproductively active females). Nevertheless, the estimated magnitude of the declining trend over the period 1980-1997 was consistent with that estimated by Caswell et al. (1999) but had lower precision. The survival rate estimated for this model was for reproductively active females in all years (calf and non-calf years) whereas the estimate in SC/O99/RW7 was for females in the year in which they had a calf.

The cluster analysis presented in SC/O99/RW2 identified four groups of individuals. The two groups containing animals primarily seen in offshore areas were male dominated whilst two groups containing animals seen in the southeastern US were female dominated. The Bay of Fundy/Scotian Shelf group contained animals formerly seen on the Scotian Shelf but seen mainly in the Bay of Fundy from 1993 onwards.

Models allowing capture probability to vary by group as well as year gave consistently better fits to the data. The best model for survival rate included variation among groups and a logistic trend over time. Estimated capture probabilities reflected changes in effort over time. For the offshore group (SS/GSC), there was a peak in the late 1980s followed by much lower values. Other groups showed increases over time. Overall, non-calf survival showed a downward trend over time. When heterogeneity in capture probabilities over groups was not accounted for, poorer fits to the data were obtained and estimates of survival were lower. The estimates from Caswell et al. (1999) were lower, reflecting differences in the analyses; they estimated crude survival rate (including calves) and used data only through 1996.

The best fitting survival model showed the greatest decline in the MASS/SEUS/BOF group ( $83 \%$ female); this was consistent with the results from other analyses presented. There were also declines estimated for the SS/GSC and BOF/SS groups but Wade expressed the concern that these might be artefacts because of a decline in sampling effort in SS and GSC after 1990 and the decline in use of Roseway Basin (in SS) after 1993. There was a slight increase in survivorship in the BOF group ( $57 \%$ female); the group for which the greatest and most consistent effort data exist.

In discussion it was noted that whales in the offshore (SS/GSC) group were mostly seen in other areas after 1990 and that this implied there was still significant spatial heterogeneity present in this group. Attention was also drawn to the comparability of the results in SC/O99/RW2 with those in Caswell et al. (1999) that included the 'offshore index' covariate, although the estimated decline in survival in SC/O99/RW2 was only about half of that in Caswell et al. (1999) and was found by the AIC to apparently account for more spatial heterogeneity than the offshore index approach.

Fujiwara presented preliminary results for North Atlantic and Southern Hemisphere right whales from a stage-specific model for reproductively active females. It was noted that differences in the time of year when animals were typically sighted in the two areas introduced difficulties in interpreting the results. Nevertheless, the Workshop agreed that this was a valuable approach and should be pursued.

The Workshop agreed that survival rate had declined from relatively high levels in the 1980s to lower levels in the 1990s. A summary of the results presented to the Workshop are given in Table 3 and Fig. 2. The greater declines estimated for females with calves might indicate that there were particular problems with this class of animals. However, results from stage-specific models for particular stages should be interpreted with some caution and declines in other stages should not be ignored. Females with calves may be vulnerable because of increased energetic requirements but calves were also vulnerable. There was limited information on calves because they are typically not identified at time of first capture. Nevertheless the best model fit from SC/O99/RW2 included constant calf survival.

\section{ASSESSMENT OF STATUS AND TRENDS}

\subsection{Results from population modelling}

Caswell presented the results from a stage and sex specific demographic model (SC/O99/RW6), which were not widely divergent from those of the previously published aggregated model (Caswell et al., 1999). Life expectancy declined from about 40 to 20 years from 1980 to 1995 . Expected lifetime reproductive events (the mean number of times that a female will give birth over her lifetime) similarly declined over the same period from about 6 to 2 for newborn animals and about 9 to 2.5 for animals at maturity. The net reproductive rate declined from about 3 to less than 1 . The population growth rate declined from 1.03 to 0.98 . Projected time to extinction varies by how long it is assumed a mother must survive to ensure survival of her calf; if this is one year, the population is predicted to be extinct within 200 years. Improving the survival rate of mature females would make most difference to the predicted fate of the population; preventing the deaths of 2-3 animals would bring the population growth rate above 1.0. However, the estimated survival rate is already 0.99 and can, therefore, increase only slightly.

The survival rate estimates for North Atlantic right whales in the 1980s are similar to survival estimates of about 0.98 from the Southern Hemisphere (SC/O99/RW1; Best et al., 2001). However, survival rate estimates for North Atlantic right whales in the 1990s are lower, while the Southern Hemisphere rates appear to have remained constant (SC/O99/RW1).

The Workshop agreed that the population modelling results (Table 3 ) indicated that survival had declined in the 1990 s relative to the 1980 s.

\subsubsection{Recommendations}

It was recognised that the incorporation of even crude measures of effort into population modelling provided better fits to data and allowed some examination of heterogeneity. Accordingly, more detailed and standardised effort data would probably permit more refined analyses. The Workshop recommends that an effort be made to tabulate effort by area, platform, type (dedicated versus opportunistic, vessel versus aerial) and by year. Kenney and Wade agreed to cooperate to achieve this before the next North Atlantic Right Whale Consortium meeting and in time for the multidisciplinary Workshop discussed under Item 8.1.2. It should include entry of raw effort data where necessary.

The Workshop also recommends the continued development of population models into which demographic parameter estimates can be incorporated. One of the goals of such models should be estimation of risk, and they should include exploration of demographic stochasticity (as in Caswell et al., 1999 and SC/O99/RW6), environmental stochasticity (especially in reproductive rates) and spatial 
structure. Linking these models to genetic factors will be one of the goals of the proposed Genetics Workshop (see Item 6.1.1 and Annex E).

\subsection{Results from population monitoring}

Knowlton presented the total number of individuals observed by year (Table 4). She noted an increase in the number of individuals recorded starting in 1994, and attributed this to a redistribution of animals from Roseway Basin into the Bay of Fundy, together with higher effort in other inshore areas.

The Workshop agreed that the available data from the NARWC and the NARWD alone could not be used to estimate trends in population size. In this context their value was in providing data for the modelling exercises discussed above. Although it appears unlikely to be practical, the Table 3

Summary of the results of models presented at the Workshop.

\begin{tabular}{|c|c|c|c|}
\hline Source & Sighting model & Measure of survival & Conclusion \\
\hline Caswell et al. 1999 & Time & Crude survival & Survival has declined \\
\hline Caswell et al. 1999 & $\begin{array}{l}\text { Time, location } \\
\text { (offshore/onshore) }\end{array}$ & Crude survival & Survival has declined \\
\hline $\begin{array}{l}\text { Caswell et al. } 1999 \text { model; Lebreton } \\
\text { analysis at Woods Hole Workshop }\end{array}$ & $\begin{array}{l}\text { Time, corrected for trap- } \\
\text { happiness and quasi-transients }\end{array}$ & Crude survival & Survival has declined $(p<0.1)$ \\
\hline $\begin{array}{l}\text { Caswell et al. } 1999 \text { model; Lebreton } \\
\text { analysis at Woods Hole Workshop }\end{array}$ & $\begin{array}{l}\text { Time, corrected as above, } \\
\text { location (BOl') }\end{array}$ & Crude survival & Survival has declined $(p<0.02)$ \\
\hline \multirow[t]{6}{*}{$\mathrm{SC} / \mathrm{O} 99 / \mathrm{RW} 7$} & Time, effort, sex, stage & Sex-stage-specific survival & Calf survival constant \\
\hline & & & Immature female survival declining \\
\hline & & & Mature female survival constant \\
\hline & & & Cow survival declining \\
\hline & & & Immature male survival increasing \\
\hline & & & Mature male survival declining \\
\hline $\mathrm{SC} / \mathrm{O} 99 / \mathrm{RW} 7$ & $\begin{array}{l}\text { Time, effort, sex, stage (calf, } \\
\text { juvenile, mature, cow) }\end{array}$ & Computed crude survival & Survival has declined \\
\hline $\mathrm{SC} / 099 / \mathrm{RW} 7$ & $\begin{array}{l}\text { Time, effort, sex, stage (calf, } \\
\text { juvenile, mature, cow) }\end{array}$ & Computed non-call survival & Survival has declined \\
\hline $\mathrm{SC} / 099 / \mathrm{RW} 2$ & $\begin{array}{l}\text { Time, location ( } 4 \text { regions), } \\
\text { stage (calf, non-calf) }\end{array}$ & Non-calf survival & Survival has declined in three of four clusters \\
\hline $\mathrm{SC} / \mathrm{O} 99 / \mathrm{RW}_{2}$ & $\begin{array}{l}\text { Time, location ( } 4 \text { regions), } \\
\text { stage (call, non-calf) }\end{array}$ & Non-calf survival, pooling areas & Survival has declined \\
\hline Cooke and Glinka & Time, location ( 2 regions) & Adult female survival & Survival has declined \\
\hline
\end{tabular}
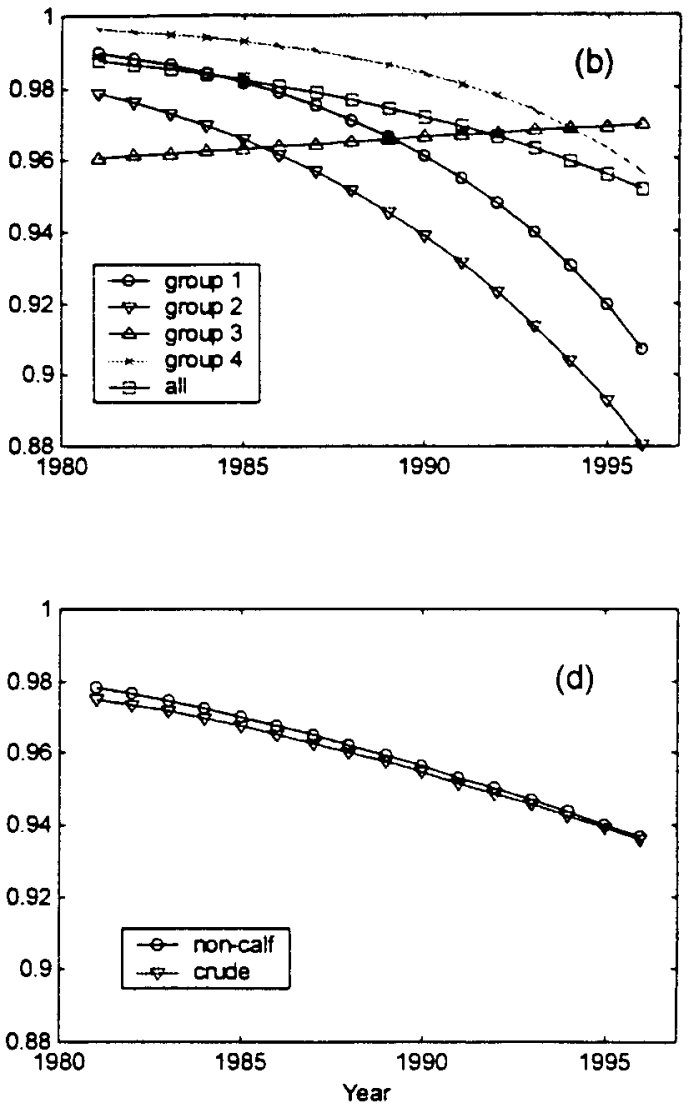

Fig. 2. This figure shows trends in survival probability from various models of the North Atlantic right whale. (a) Crude survival from three sighting models: one a function of time only, one a function of time but eliminating all 'strictly offshore' whales from the data, and one a function of time and of an offshore index as an individual covariate (from Caswell et al., 1999). (b) Group-specific non-calf survival with sighting a function of group and time (group 1 = MASS/SEUS/BOF; group $2=\mathrm{SS} / \mathrm{GSC}$; group $3=\mathrm{BOF}$; group $4=\mathrm{BOF} / \mathrm{SS}$ ) and an estimate of non-calf survival pooled over all four groups (from SC/O99/RW2). (c) Mature female survival with sighting a function of time and location (from SC/O99/RW1). (d) Crude survival and non-calf survival computed from the stage-sex-specific model of SC/O99/RW7. Sighting probability is a function of time, effort, sex, and stage. Crude and non-calf survival probabilities calculated as weighted averages of sex-stage-specific survival probabilities. 


\section{Table 4}

Summary of annual sightings of total numbers of individuals and numbers of individuals sighted in each area. Note: one individual can be sighted in numerous areas in a given year but will only be counted once in the total number of individuals. Abbreviations: SEUS, southeast U.S.; MB, Massachusetts Bay; GSC, Great South Channel; BOF, Bay of Fundy; BB, Browns Bank/Roseway Basin; North, North and east of Browns Bank/Roseway Basin; Mid Atl., mid Atlantic between South Carolina and Cape Cod.

\begin{tabular}{|c|c|c|c|c|c|c|c|c|c|c|}
\hline \multirow[b]{2}{*}{ Year } & \multirow[b]{2}{*}{ Sightings } & \multirow[b]{2}{*}{ Individuals } & \multicolumn{8}{|c|}{ No. of individuals photographed } \\
\hline & & & SEUS & MB & GSC & $\mathrm{BOF}$ & $\mathrm{BB}$ & North & Mid Atl. & Other \\
\hline 1980 & 120 & 62 & 0 & 5 & 19 & 23 & 13 & 0 & 2 & 17 \\
\hline 1981 & 336 & 103 & 2 & 8 & 62 & 56 & 0 & 1 & 0 & 7 \\
\hline 1982 & 405 & 99 & 3 & 13 & 20 & 52 & 30 & 0 & 2 & 9 \\
\hline 1983 & 280 & 76 & 3 & 30 & 7 & 26 & 26 & 0 & 2 & 4 \\
\hline 1984 & 423 & 114 & 15 & 28 & 22 & 54 & 29 & 0 & 5 & 11 \\
\hline 1986 & 907 & 152 & 23 & 54 & 27 & 42 & 80 & 0 & 5 & 6 \\
\hline 1987 & 458 & 152 & 14 & 39 & 40 & 31 & 82 & 2 & 2 & 1 \\
\hline 1988 & 579 & 197 & 9 & 29 & 94 & 44 & 118 & 0 & 0 & 10 \\
\hline 1989 & 899 & 206 & 41 & 21 & 39 & 74 & 115 & 2 & 4 & 8 \\
\hline 1990 & 502 & 148 & 32 & 29 & 0 & 68 & 47 & 1 & 1 & 9 \\
\hline 1991 & 384 & 158 & 20 & 33 & 9 & 51 & 90 & 0 & 1 & 2 \\
\hline 1992 & 584 & 130 & 26 & 45 & 0 & 72 & 17 & 1 & 0 & 9 \\
\hline 1993 & 608 & 177 & 53 & 41 & 0 & 148 & 0 & 1 & 5 & 7 \\
\hline 1995 & 1,543 & 216 & 25 & 64 & 2 & 187 & 5 & 1 & 1 & 2 \\
\hline 1996 & 1,539 & 216 & 98 & 78 & 4 & 168 & 0 & 2 & 5 & 45 \\
\hline 1997 & 2,170 & 230 & 46 & 57 & 10 & 199 & 3 & 1 & 0 & 9 \\
\hline 1998 & 979 & 188 & 27 & 85 & 22 & 106 & 0 & 9 & 13 & 8 \\
\hline
\end{tabular}

Workshop recommends investigation of the feasibility of conducting a dedicated, standardised survey to assess right whale population size and trends.

Given the central importance of the NARWC to population assessment and to the monitoring of the effectiveness of management actions, the Workshop strongly recommends continued funding for this effort, its compilation, and the fieldwork that underpins it.

\subsection{Factors affecting trends}

\subsubsection{Direct anthropogenic interactions}

The Workshop strongly believes that reducing the impacts of anthropogenic activities (fishing and shipping) on the North Atlantic right whale population should be the primary focus of future research and management actions (see Item 8). Mortalities and serious injuries of right whales have been documented since 1970 (Knowlton and Kraus, 2001). The data suggest that the level of mortalities attributable to human activities has been increasing over time, however this increase could be due to increased reporting of carcasses and increased efforts to retrieve and necropsy them. The total number of mortalities documented between 1970 and 1999 is 45 (16 due to ship collisions, 3 due to entanglement, 13 neonates, and 13 of unknown cause).

Knowlton and Kraus (2001) developed a set of criteria for defining a serious injury from entanglement or ship strike to assess how many animals have suffered injuries that could lead to death. For entanglement, this includes any animal carrying line, any animal with a wound deeper than $8 \mathrm{~cm}$ caused by entanglement, or any animal that appears to be in poor health from entanglement. For ship strikes, seriously injured animals are those with propeller cuts or gashes deeper than $8 \mathrm{~cm}$, evidence of bone breakage determined to have occurred pre-mortem, or evidence of haemorrhaging or haematoma. These serious injuries were further subdivided into impact levels of fatal, possibly fatal and non-fatal. Under these criteria, 56 serious injuries have been documented between 1970 and 1999: 31 from entanglement and 25 from ship strikes. Nineteen were fatal (16 ship strikes,
3 entanglements), 13 were possibly fatal ( 2 ship strikes, 11 entanglements), and 24 were non-fatal (7 ship strikes, 17 entanglements).

The annual rate of increase of all serious injuries and mortalities is $5.65 \%$ (95\% CI $=1.32-9.98 \%$ - 1970-1998). This rate exceeds the estimated average annual rate of increase of the population, which has ranged from $4.4 \%$ to $-2.4 \%$ (Caswell et al., 1999). This suggests that this increase in serious injury and mortality is not correlated with population size. The data also indicate that anthropogenic interactions are responsible for a minimum of two thirds of the confirmed and possible mortalities of non-neonate animals. The estimates do not take into account changing effort.

The recommendations of the Workshop are given under Item 8.

\subsubsection{Habitat degradation}

Kenney summarised results of the South Channel Ocean Productivity Experiment (SCOPEX), which concluded that successful right whale feeding depends on extremely dense zooplankton patches (e.g. Kenney et al., 1986; Wishner et al., 1988; Mayo and Marx, 1990; Kenney and Wishner, 1995). Patch development is primarily a physical rather than biological phenomenon. Consequently, changes in oceanographic conditions can alter extent, location, timing and persistence of acceptable or optimal feeding grounds. Overall non-tidal circulation in the Gulf of Maine is driven by the influx of Scotian Shelf Water across the shelf south of Cape Sable, Nova Scotia and at depth inward through the Northeast Channel. An analysis of oceanographic affects on right whale distribution (Kenney, 2001) concluded that the absence of right whales in the Great South Channel in 1992 resulted from the greatly reduced abundance of Calanus that resulted from significantly lower water temperatures and consequential hydrographical changes. The underlying cause was an unusually large influx of cooler and fresher Scotian Shelf Water, observed on Georges Bank in April for the first time, possibly exacerbated by the global cooling effect from the 1991 eruption of the Mt Pinatubo volcano. 
Kenney also described another analysis (SC/M98/RW29), correlating calving rate with the annual mean Southern Oscillation Index (SOI) lagged by one year, with low calving years tending to occur one year after El Niño events. Another correlation was found between calving rate and the North Atlantic Oscillation (NAO) lagged by two years. A regression model including both variables predicted eight calves would be born in 1999, when the observed number was four. Hindcasting from the model back to 1982, the absolute value of the difference between predicted and observed was 2.4, ranging from 3.5 higher than observed in 1995 to 8.1 lower than observed in 1996. Updating the model to include the 1999 calves and atmospheric data, plus a recent NARWC correction for 1984, the significant effects are still from SOI lagged one year and NAO lagged two years. It predicts 14 calves in 2000 . The observed increase in calving intervals was primarily between 1992 and 1993 rather than a gradual trend, coinciding in time with observed distributional shifts (i.e. the abandonment of Roseway Basin). This is consistent with a hypothesis that changes in oceanographic conditions have altered foraging grounds. Kenney suggested that energy limitation is an underlying cause of the reproductive changes.

As noted under Item 6.4, the Workshop could reach no conclusions on the food limitation hypothesis.

Kenney also hypothesised (Kenney et al., 2001) that the present population is a remnant on the periphery of its historical range that has not re-occupied the original core of the range because of strong maternally-directed site fidelity. Such a peripheral segment of a population might be expected to undergo fluctuations in feeding and reproductive success with environmental variation, which might over the long term maintain low abundance. As with the previous hypothesis, insufficient data are available to confirm or refute this hypothesis.

Moore summarised results of work on right whale blubber thickness (SC/O99/RW4). Blubber thicknesses of necropsied northern right whales were consistently less than observed in southern right whales (Tormosov, 1998) when blubber thickness is plotted against body length. It was noted that because the sampled northern right whales were mostly ship-struck their blubber thickness would not have been compromised by reduced health prior to death. A small sample of randomly selected blubber thickness measurements obtained acoustically in 1999 from adults from the above two species (for methods, see Moore et al., 2001) also revealed that northern right whales had lower blubber thickness than their southern counterparts. Although no relationship was found between acoustically measured blubber thickness and age in male northern right whales, females' blubber thickness increased with age. Those females that had calved showed a correlation between increasing blubber thickness and number of years since calving.

Moore discussed the possibility of using blubber biopsy contaminant burdens of halogenated hydrocarbons, and related biochemical indices, to predict potential internal organ toxicological risk (SC/M98/RW24). Both northern and southern right whales, from different ocean basins, have consistently low organochlorine burdens, as predicted by other studies in right whales and other mysticetes. However, the induction of endothelial cytochrome P 450 1A (CYP1A) was elevated in samples from feeding northern right whales, as compared to calving northern right whales, and to calving and feeding southern right whales. Since these assays detect presence of chemicals that are not accumulated, positive findings indicate current and continuing exposure. Moore concluded that these levels warrant further monitoring. The Workshop noted that further work is required to interpret how pollutant levels relate to the health of marine mammals (Reijnders et al., 1999).

The Workshop also noted that there are a number of widely used compounds only recently recognised as potentially toxic or endocrine-disruptive at ambient oceanic levels including tributyltins (anti-fouling compounds used on ships worldwide), nonylphenols (dispersants used widely in detergents), polybrominated biphenyls, polybrominated diphenyl ethers and phthalates (plasticisers). Few of these have been tested in marine mammals, and none have been tested in right whales.

Marx described three different types of skin lesions seen. There is clear evidence of a steady increase of such lesions through time. Animals have been observed to recover from them. Their cause remains unknown and it was recommended that in addition to the veterinarians already consulted, dermatologists be employed to diagnose the whales' condition. Lesions and scars were also discussed at a New England Aquarium workshop on the effects of tagging in October 1999. Its report will be made available to the Scientific Committee in 2000.

\subsubsection{RECOMMENDATIONS}

The Workshop endorsed the previous recommendations of the Cape Town Workshop (IWC, 2001) that coordinated studies of health in right whales should be undertaken, from using both biopsy- and necropsy-derived samples. Where possible, researchers should:

(a) obtain biopsy and/or necropsy samples of the skin lesions for histology and microbiology;

(b) examine histology samples and necropsy data from all right whale mortalities.

Such studies will be greatly enhanced if all workers follow the standard approach to reporting necropsies discussed at Cape Town (IWC, 2001).

The Workshop also recommends that:

(1) methods of assessing the health of right whales be investigated, including continued monitoring of the prevalence and incidence of skin lesions;

(2) the feasibility of applying techniques designed to investigate stress in other cetacean species using skin biopsies and faecal samples (e.g. by the Southwest Fisheries Science Center) be explored with regard to their applicability to right whales; and

(3) an evaluation of the feasibility and efficacy of medical interventions for right whales in extreme circumstances be undertaken.

With respect to pollutant studies, the Workshop endorsed the three following (slightly modified) recommendations from the Cape Town Workshop (IWC, 2001) that:

(1) extant and future necropsy and biopsy samples should be analysed for PCBs, pesticides and dioxins, as well as certain newer contaminants such as tributyltins, phthalates and nonylphenols;

(2) routine monitoring of CYP1A expression in right whales should be implemented;

(3) copepod and krill samples from known or presumed feeding habitats in both hemispheres should be analysed for PCBs, pesticides and dioxins.

However, the Workshop recognised the importance of continuing parallel studies of cause-effect relationships in contaminants, without which interpretation of levels is 
impossible. Sample sizes from right whale studies alone will inevitably be too small. Thus, the Workshop strongly recommends support for the Commission's POLLUTION 2000+ project (IWC, 1999a) and agrees that right whale studies should be linked to those ongoing investigations.

Given the probable link between body condition and reproductive success, the Workshop recommends that seasonal and annual body condition dynamics in each habitat and reproductive class should be studied and that girth and blubber thickness measurements be taken during all right whale necropsies. Such information will also be of value in interpreting the results of pollutant analyses.

Finally, the Workshop endorsed the Cape Town Workshop recommendation (IWC, 2001) that local, regional and national authorities responsible for right whale habitat should develop contingency plans for oil and chemical spills.

\subsubsection{Population structure and recruitment}

Both sightings and genetic data support the possibility of maternally directed philopatry to the Bay of Fundy and to an alternative (currently unidentified) nursery area (SC/O99/RW7). Genetic data also suggest restricted gene flow between the Bay of Fundy and the non-Fundy group, and raises the possibility of the existence of two mating grounds.

Genetic analyses have attempted to assign the first-order relatedness of animals of unknown age to other individuals in the population; these have produced a surprisingly low match rate, which suggests that more calving events are being missed than is assumed. It is not clear whether this is due to mother/calf pairs being unrecorded in the southeastern USA, to the existence of another calving ground, to the appearance in the population of individuals born and not observed in the earlier part of the study period (as suggested by population models), or to a slightly larger population size.

The Workshop agreed that information on genetic structure of different feeding areas should be incorporated into future risk analyses for those areas. This is discussed further in the context of the proposed genetics Workshop (Annex E).

\subsubsection{Inbreeding}

Results from reproductive analyses showing that the North Atlantic right whale has a lower birth rate and longer interbirth intervals than the southern right whale might indicate the existence of inbreeding (mating between animals that are related by descent). However, there is no evidence from completed kinship analyses of paternity assignments to sampled mother/calf pairs to indicate inbreeding in this population. This is further supported by the lack of heterozygote deficiency in the population, which indicates no departure from the Hardy-Weinberg equilibrium (Ralls et al., 1986).

MHC analysis in humans indicates that foetuses which share the same MHC type as their mother are more likely to be aborted than those with different genotypes. Analysis of MHC diversity in northern right whales may provide insights into whether this is a possible explanation for the depressed reproduction in this population.

The Workshop noted that analysis of microsatellites suggests that this population has not gone through a bottleneck within the last 150 years. Additional analyses further suggest that the population has been small for several hundred years; if true, this may have resulted in the purging of deleterious alleles, but may have compromised MHC diversity. Predictions from this hypothesis include: that females with low fecundity in this population should show the most common MHC haplotypes; and that $16^{\text {th }}$ century specimens from Red Bay, as well as South Atlantic right whales, should both show higher MHC diversity than the current North Atlantic population.

\subsection{Comparison with other populations}

Best et al. (2001) calculated demographic parameters of southern right whales off South Africa. Results included a mean calving interval of 3.12 years $(95 \% \mathrm{CI}$ 3.07-3.17), an adult female survival rate of 0.983 (95\% CI 0.972-0.994), median age at first parturition 7.88 years (95\% CI 7.17-9.29), first-year survival rate of 0.913 (95\% CI 0.601-0.994), and instantaneous population increase rate of 0.071 (95\% CI $0.059-0.082)$. These biological parameter estimates were compatible with the observed increase rate of the population without the need to postulate immigration.

The data presented in Table 2 indicate a relatively low rate of reproduction in the North Atlantic. Although strictly comparable data are not available for the Southern Hemisphere, by inference reproductive rates for the latter are higher. There is a significant number of North Atlantic right whale females that never calve. In contrast, the reproductive rate in southern right whales precludes this possibility in that population.

\section{CONCLUSION AND RECOMMENDATIONS}

In discussing Recommendations, the Workshop agreed to separate out at least two aspects of the issues being discussed when deciding a strategy for the future. These can be seen as:

(1) research that enables us to document and gain scientific insights into population dynamics and ecology of a whale population that has been reduced both to very low absolute numbers as well as a small fraction of its original population size;

(2) research that will permit implementation of appropriate management actions and evaluation of their performance.

Whilst both the above are important, and recommendations for both have been developed, it was agreed that the highest priority must be accorded to the latter category. Despite the improvements that can and should be made in terms of refining the modelling of this population, it is clear that none of those refinements will lead to a change in the conclusion that:

by any management criteria applied by the IWC in terms of either commercial whaling or aboriginal subsistence whaling, there should be no direct anthropogenic removals from this stock.

The evidence that this population (possibly the only potentially viable population of this species) is in serious danger is compelling, and the need for further research under category (1) above should not be seen as a reason for delaying immediate and highest priority action under (2). In short, this population:

(a) is at very low absolute abundance and thus highly vulnerable to stochastic variation in population dynamic processes; 
(b) is, unlike a number of Southern Hemisphere populations, not recovering despite protection from whaling since the 1930s;

(c) appears to be decreasing at present as a result of

(i) a decreased rate of survival in the 1990s versus the 1980s;

(ii) an increase in effective calving interval in the 1990s;

(d) is subject to known direct anthropogenic removals (ship strikes and entanglements in fishing gear) that have been increasing in recent years.

In addition, there is some evidence that the overall health of the population has decreased since the 1980s (e.g. as witnessed by increased incidence of skin lesions).

Given all the above, the Workshop agreed that it is a matter of absolute urgency that every effort is made to reduce anthropogenic mortality to zero. This is perhaps the only way in which the chances of survival for this population can be directly improved. Research directed at this aim should be given immediate priority.

\subsection{Research}

\subsubsection{General}

A number of recommendations were developed and are discussed under the relevant Agenda Items. Table 5 summarises these, their aims and their relevance to the two research categories noted above. The Workshop believes that all of the recommendations are of importance. However, it agrees that given the present status of this population as documented above, it is important to assign levels of priority to the research recommendations, as shown in Table 5.

\subsubsection{Highest priority}

Records of deaths and injuries indicate that two-thirds of non-calf mortality events could be due to entanglements and ship strikes (Knowlton and Kraus, 2001). Given the failure of current methods to eliminate all sources of mortality from shipping and fishing in North Atlantic right whales, the Workshop recognises that only drastic measures, such as total restrictions on fixed fishing gear and shipping, would immediately accomplish the goal of zero mortality. Since such total restrictions are not feasible, research is urgently needed on the development of methods to eliminate both sources of mortality. Nevertheless, the Workshop strongly emphasises that there is no need to wait for further research before implementing any currently available management actions that can reduce anthropogenic mortalities.

In that context, the Workshop recommends that the highest priority be assigned to research into means of reducing mortality from entanglements and vessel collisions. It further recommends that an international multidisciplinary Workshop be held to review progress and to identify priorities for further work and the most promising approaches to management action to reduce mortality. That multidisciplinary Workshop will review ongoing work on inter alia:

(1) the determination of risk factors for collisions and entanglements (such as analyses of vessel traffic and fishing activity patterns with respect to right whale distribution and risk);

(2) use of modelling to identify areas or classes of animals that are subject to particularly high risk;

(3) the use of shipborne, aerial and fixed (acoustic) surveys for real-time monitoring of right whale concentrations;

(4) the efficacy and feasibility of different approaches to managing shipping movements for right whale avoidance, such as ship rerouting and/or speed reductions, using both computer simulations and field trials;

(5) the awareness of mariners in the region to right whale issues and their response to information and directions relating to right whale avoidance;

(6) cross-disciplinary evaluation of disentanglement and gear modification technologies.

It is essential that every effort be made to ensure that requisite data are available. At a minimum this must include, for the entire east coast of North America, good temporal and geographical information on vessel traffic, fishing gear effort and distribution. The Workshop recommends that the Commission urges the relevant governments to ensure that such data are recorded, collated and made available. In this context, the Workshop recommends that a Geographic Information System (GIS) project be conducted to overlay effort data (see Item 7.2.1) onto information on right whale distribution together with that of fishing gear, shipping activity and other threats.

For the multidisciplinary Workshop to be successful it is important that relevant national and international organisations are invited as well as experts in right whale biology, shipping technology, fishing gear, etc. It was agreed that Knowlton and Kraus should identify an appropriate Steering Group to inter alia:

(1) identify potential participants and request papers;

(2) identify a suitable venue and time;

(3) draw up an agenda and structure for the meeting.

Notwithstanding that the above recommendation should be accorded highest priority, the Workshop also recognises that reduced calving success may reflect the impact of a variety of human activities that alter coastal habitats (e.g. altered food resources, elevated contaminant levels and behavioural disruption). It therefore recommends that research on these and other habitat quality issues be intensified and that the habitat Workshop referred to under Item 7 evaluate the impact and mitigation of habitat stressors.

\subsection{Management}

The Workshop reiterates that it is a matter of absolute urgency that every effort is made to reduce anthropogenic mortality in this population to zero. This is perhaps the only way in which its chances of survival can be directly improved. There is no need to wait for further research before implementing any currently available management actions that can reduce anthropogenic mortalities.

Knowlton noted that an information document to shift shipping lanes in the Bay of Fundy had been submitted to the International Maritime Organisation (IMO). To reduce the potential for ship/whale collisions, the Workshop recommends that a document summarising right whale sightings data, corrected for effort, be presented as a proposal to IMO for consideration of alternate routing of vessels away from areas of high right whale density.

In light of the recently implemented Mandatory Ship Reporting System in this area, the Workshop recommends that the data on number of ships entering the area and the speeds at which they are travelling be investigated. It further recommends that the distribution of whales be overlaid with traffic distribution and shipping lanes to assess the need and feasibility of further regulatory actions related to ship routing and reduction of ship speed.

In addition to those described above, the following actions have been taken regarding recommendations made by the 
Table 5

Summary of recommendations (high priority marked with an asterisk). (Cat.1 = research that enables us to document and gain scientific insights into the population dynamics and ecology. Cat. 2 = research that will enable us to carry out appropriate management actions and evaluate their performance.)

Agenda

Item Brief objective

Cat. 1 Cat. 2 Priority Timescale Comments

Anthropogenic removals (highest priority)

8.1.2 Workshop on ship strikes and entanglements

7.1.1 Tabulating effort data

8.1.2 GIS analysis of right whale distribution relative to geographic and risk factors

8.1.2 Collect/collate good temporal and geographical information on vessel traffic, fishing gear

NARWC - related long-term monitoring

7.2.1 Continuation of NARWC and related field effort

4.1 Code identification photographs for distinctiveness and photo quality

4.1 Goodness of fit testing for heterogeneity

4.1 Automated matching

Genetics - related studies

6.1.1 Genetics workshop

6.1.1 Multilocus genotyping of all individuals, and use of markers to determine substock structure

6.1.1 Genotyping at MHC loci for correlations with reproductive success and health

7.1.1 Continued development of population models

6.1.1 Conducted directed biopsy sampling, especially in the southeastern USA

6.1.1 Genetic analysis of historical specimens to examine population structure and genetic diversity

6.1.1 Conduct genetic analysis with respect to habitat use, scarring patterns, reproductive success and resighting probabilities

Health - related studies

7.3.2.1 Evaluate possible methods for health assessment, including monitoring of skin lesions

7.3.2.1 Feasibility study on stress investigation

7.3.2.1 Evaluation of medical interventions

Pollutant - related studies

7.3.2.1 Link of pollution studies to POLLUTION 2000+

7.3.2.1 Collect and analyse right whale samples for contaminants

7.3.2.1 Monitor CYP1A expression

7.3.2.1 Collect and analyse zooplankton samples for study of contaminants

Habitat - related studies

8.1.2 Conduct habitat workshop

6.4.1 Obtain length measurements of individual right whales for use in assessments of health, age and blubber thickness

7.3.2.1 Blubber thickness studies

Other

7.2.1 Examine feasibility of a coordinated dedicated assessment survey

\begin{tabular}{|c|c|c|c|}
\hline Yes & $A^{*}$ & $\mathrm{Ca} 1$ year & Aim for ?? date ?? \\
\hline Yes & A & 1 year & $\begin{array}{l}\text { Relevant to shipstrike and } \\
\text { entanglement workshop }\end{array}$ \\
\hline Yes & A & 1 year+ & $\begin{array}{l}\text { Relevant to shipstrike and } \\
\text { entanglement workshop }\end{array}$ \\
\hline Yes & A & 1 year & $\begin{array}{l}\text { Relevant to shipstrike and } \\
\text { entanglement workshop }\end{array}$ \\
\hline
\end{tabular}

Yes Yes A* Ongoing Relevant to all work - very high

Yes Yes A Ongoing

Yes $\quad$ C Unclear

Yes $\quad$ C 1 year

Yes Yes A* 1 year+ Aim for October 2000

Yes Yes A 1 year Completion required before

genetics workshop

Yes A 1 year Completion required before

genetics workshop

Yes Yes A Relevant to genetics workshop

Yes Yes A Ongoing

Yes B Unclear Relevant to genetics workshop

Yes Yes B 2 years Relevant to genetics workshop

$\begin{array}{cccl}\text { Yes } & \text { Yes } & \text { A } & \begin{array}{l}\text { 1 year } \\ \text { (prelim) }\end{array} \\ \text { Yes } & & \text { B } & ?\end{array}$

Yes Yes A 5 years

Yes Yes B Years

Yes Yes B Years

Yes Yes C Years

Yes Yes A 2 years+ See SC environment group

Yes A Years

Yes Yes

Yes

C 1 day
Cape Town Workshop (see IWC, 2001c, appendix 1 of annex $\mathrm{O})$ :

(1) Movement of major shipping channels in the southeastern USA calving ground: this remains in discussion.

(2) Consideration of risks to right whales in permit review for high-speed ferry operations: this is legally complex but is being investigated further.

\section{OTHER BUSINESS}

The Workshop offered its warm thanks to Clapham and the NEFC Science Center for their courtesy and the provision of excellent facilities. The Chairman, despite avoiding the final session, was applauded for his usual firm but fair and good-natured chairing of the meeting. Thanks are also due to the Steering Group and the Rapporteurs, and to Clare Last and Martin Harvey of the IWC Secretariat who assisted with the administration.

\section{REFERENCES}

Akaike, H. 1973. Information theory and an extension of the maximum likelihood principle. pp. 267-81. In: B.N. Petran and F. Csaàki (eds.) International Symposium on Information Theory. 2nd. Edn. Akadèemiai Kiadi, Budapest, Hungary. 451pp.

Best, P.B. and Rüther, H. 1992. Aerial photogrammetry of southern right whales, Eubalaena australis. J. Zool., London. 228:595-614.

Best, P.B., Brandão, A. and Butterworth, D. 2001. Demographic parameters of southern right whales off South Africa. J. Cetacean Res. Manage. (special issue) 2:161-169.

Brault, S. and Caswell, H. 1993. Pod-specific demography of killer whales (Orcinus orca). Ecology 74(5):1444-54.

Brown, M.W., Kraus, S.D., Gaskin, D.E. and White, B.N. 1994. Sexual composition and analysis of reproductive females in the North Atlantic right whale, Eubalaena glacialis, population. Mar. Mammal Sci. 10(3):252-65.

Buckland, S.T. 1990. Estimation of survival rates from sightings of individually identifiable whales. Rep. int. Whal. Commn (special issue) 12:149-53.

Burnell, S.R. and Shanahan, D. 2001. A note on a prototype system for simple computer-assisted matching of individually identified southern right whales, Eubalaena australis. J. Cetacean Res. Manage. (special issue) 2:297-300. 
Caswell, H., Fujiwara, M. and Brault, S. 1999. Declining survival probability threatens the North Atlantic right whale. Proc. Natl Acad. Sci. USA 96:3308-13.

Cooke, J.G., Rowntree, V. and Payne, R. 2001. Estimates of demographic parameters for southern right whales (Eubalaena australis) observed off Peninsula Valdés, Argentina. J. Cetacean Res. Manage. (special issue) 2:125-132.

Gordon, J.C.D. 1990. A simple photographic technique for measuring the length of whales from boats at sea. Rep. int. Whal. Commn 40:581-8.

Hamilton, P.K., Marx, M.K. and Kraus, S.D. 1995. Skin lesions in Northern right whales. Proceedings of the 11th Biennial Conference on the Biology of Marine Mammals, 14-18 December 1995, Orlando, FL. p.49. [Abstract].

Hammond, P.S. 1986. Estimating the size of naturally marked whale populations using capture-recapture techniques. Rep. int. Whal. Commn (special issue) 8:253-82.

Hammond, P.S., Mizroch, S.A. and Donovan, G.P. (eds.). 1990 Individual Recognition of Cetaceans: Use of Photo-Identification and Other Techniques to Estimate Population Parameters. Reports of the International Whaling Commission, Special Issue 12 , Cambridge, UK. [vi]+440pp.

International Whaling Commission. 1999a. Planning Workshop to Develop a Research Programme to Investigate Pollutant Cause-effect Relationships in Cetaceans - 'POLLUTION 2000+'. J. Cetacean Res. Manage. (special issue) 1:55-72.

International Whaling Commission. 1999b. Report of the Scientific Committee. J. Cetacean Res. Manage. (Suppl.) 1:1-52.

International Whaling Commission. 1999c. Report of the Scientific Committee. Annex E. Report of the Sub-Committee on Other Great Whales. J. Cetacean Res. Manage. (Suppl.) 1:117-55.

International Whaling Commission. 2000a. Report of the Scientific Committee. J. Cetacean Res. Manage. (Suppl.) 2:1-65.

International Whaling Commission. 2000b. Report of the Scientific Committee. Annex G. Report of the sub-committee on the Comprehensive Assessment of Other Whale Stocks. J. Cetacean Res. Manage. (Suppl.) 2:167-208

International Whaling Commission. 2001. Report of the Workshop on the Comprehensive Assessment of Right Whales: A worldwide comparison. J. Cetacean Res. Manage. (special issue) 2:1-60.

Kenney, R.D. 2001. Anomalous 1992 spring and summer right whale (Eubalaena glacialis) distributions in the Gulf of Maine. J. Cetacean Res. Manage. (special issue) 2:209-223.

Kenney, R.D. and Wishner, K.F. 1995. The South Channel Ocean productivity experiment. Cont. Shelf Res. 15(4-5):373-84.

Kenney, R.D., Hyman, M.A.M., Owen, R.E., Scott, G.P. and Winn, H.E. 1986. Estimation of prey densities required by western North Atlantic right whales. Mar. Mammal Sci. 2(1):1-13.

Kenney, R.D., Mayo, C.A. and Winn, H.E. 2001. Migration and foraging strategies at varying spatial scales in western North Atlantic right whales: a review of hypotheses. J. Cetacean Res. Manage. (special issue) 2:251-260.
Knowlton, A. and Kraus, S. 2001. Mortality and serious injury of northern right whales (Eubalaena glacialis) in the western North Atlantic Ocean. J. Cetacean Res. Manage. (special issue) 2:193-208.

Kraus, S., Hamilton, P., Kenney, R., Knowlton, A. and Slay, C. 2001. Reproductive parameters of the north Atlantic right whale. $J$. Cetacean Res. Manage. (special issue) 2:231-236.

Lockyer, C. 1984. Review of baleen whale (Mysticeti) reproduction and implications for management. Rep. int. Whal. Commn (special issue) 6:27-50.

Malik, S., Brown, M.W., Kraus, S.D., Knowlton, A.R., Hamilton, P.K. and White, B.N. 1999. Assessment of mitochondrial DNA structuring and nursery use in the North Atlantic right whale (Eubalaena glacialis). Can. J. Zool. 77:1-6.

Malik, S., Brown, M.W., Kraus, S.D. and White, B.N. 2000. Analysis of mitochondrial DNA diversity within and between North and South Atlantic right whales. Mar. Mammal Sci. 16(3):545-58.

Mayo, C.A. and Marx, M.K. 1990. Surface foraging behaviour of the North Atlantic right whale, Eubalaena glacialis, and associated zooplankton characteristics. Can. J. Zool. 68:2214-20.

Moore, M., Miller, C.A., Morss, M.S., Arthur, R., Lange, W.A. and Marx, M.K. 2001. Ultrasonic measurement of blubber thickness in right whales. J. Cetacean Res. Manage. (special issue) 2:301-309.

Ralls, K., Harvey, P.H. and Lyles, A.M. 1986. Inbreeding in natural populations of birds and mammals. pp. 35-6. In: M.E. Soul (ed.) Conservation Biology: the Science of Scarcity and Diversity. Sinauer Associates, Sunderland, Massachusetts.

Reijnders, P.J.H., Donovan, G.P., Aguilar, A. and Bjørge, A. 1999. Report of the Workshop on Chemical Pollution and Cetaceans, March 1995, Bergen, Norway. J. Cetacean Res. Manage. (special issue) $1: 1-42$.

Rosenbaum, H.C., Egan, M.G., Clapham, P.J., Brownell, R.L., Malik, S., Brown, M., White, B.N., Walsh, P. and DeSalle, R. 2000. World-wide genetic differentiation of Eubalaena: questioning the number of right whale species. Mol Ecol. 9(11):1793-1802.

Schaeff, C.M., Kraus, S.D., Brown, M.W., Perkins, J.S., Payne, R.S. and White, B.N. 1997. Comparisons of genetic variability of North and South Atlantic right whale (Eubalaena) using DNA fingerprinting. Can. J. Zool. 75:1073-80.

Tormosov, D.D. 1998. Some data on the right whale, E. glacialis, by materials of 1960-1970. Paper SC/M98/RW40 presented to the IWC Special Meeting of the Scientific Committee towards a Comprehensive Assessment of Right Whales Worldwide, 16-25 March, Cape Town, South Africa (unpublished). [Paper available from the Office of this Journal.]

Waldick, R.C., Brown, M.W. and White, B.N. 1999. Characterization and isolation of microsatellite loci from the endangered North Atlantic right whale. Mol. Ecol.

Wishner, K., Durbin, E., Durbin, A., MacAulay, M., Winn, H. and Kenney, R. 1988. Copepod patches and right whales in the Great South Channel off New England. Bull. Mar. Sci. 43(3):825-44. 


\section{Annex A \\ List of Participants ${ }^{1}$}

John Bannister

c/o Western Australian Museum

Francis Street

Perth

Western Australia 6000

AUSTRALIA

Tel: (00 61) 894272716

Fax: (00 61) 894272882

E-mail: 106174.3301@compuserve.com

Don Bowen

Department of Fisheries and Oceans

Bedford Institute of Oceanography

Nova Scotia

B2Y 4A2

CANADA

Tel: (00 1) 9024268909

Fax: (00 1) 9024261506

E-mail: bowend@mar.dfo-mpo.gc.ca

Solange Brault

Department of Biology

UMASS/Boston

100 Morrissey Boulevard

Boston, MA 02125-3393

USA

Tel: (00 1) 6172876683

Fax: (00 1) 6172876650

E-mail:brault@umbsky.cc.umb.edu

\section{Moira Brown}

Center for Coastal Studies

P.O. Box 1036

59 Commercial Street

Provincetown, MA 02657

USA

Tel: (00 1) 5084873622

Fax: (00 1) 5084874495

E-mail: brown@coastalstudies.org

Bob Brownell

Southwest Fisheries Science Center PO Box 271

La Jolla, CA 92038

USA

Tel: (00 1) 8585467165

Fax: (00 1) 8585465653

E-mail: robert.brownell@noaa.gov

${ }^{1}$ All phone/fax nos are as dialled from the UK.
Steve Burnell

Australian Marine Mammal Research Centre

University of Sydney/Taronga Zoo

c/o 25 Seaview Road

Tennyson

SA 5022

AUSTRALIA

Tel: (00 1) 914299399

Fax: (00 61) 883562290

E-mail: sburnell@bigfoot.com

Doug Butterworth

Department of Mathematics and

Applied Mathematics

University of Cape Town

Rondebosch 7701

SOUTH AFRICA

Tel: (00 27) 216502343

Fax: (00 27) 216502334

E-mail:dll@maths.uct.ac.za

Hal Caswell

Biology Dept

Woods Hole Oceanographic Institution

Woods Hole, MA 02543

USA

Tel: (00 1) 5082892751

Fax: (00 1) 5084572134

E-mail: hcaswell@whoi.edu

Phil Clapham

Northeast Fisheries Science Center

166 Water Street

Woods Hole, MA 02543

USA

Tel: (00 1) 5084952316

Fax: (00 1) 5084952066

E-mail: phillip.clapham@noaa.gov

Justin Cooke

Centre for Ecosystem Management Studies

Mooshof

D-79297 Winden

GERMANY

Tel: (00 49) 76816018

Fax: (00 49) 76816019

E-mail:jgc@cems.de 
Greg Donovan

International Whaling Commission

The Red House

135 Station Road

Impington, Cambridge

CB4 9NP

UK

Tel: (01223) 233971

Fax: (01223) 232876

E-mail: gregiwc@compuserve.com

Nancy Friday

Protected Species Branch

Northeast Fisheries Science Center

166 Water Street

Woods Hole, MA 02543

USA

Tel: (00 1) 5084952397

Fax: (00 1) 5084952256

E-mail: nancy.friday@noaa.gov

Masami Fujiwara

Biology Dept.

Woods Hole Oceanographic Institution

Woods Hole, MA 02543

USA

Tel: (00 1) 5082893254

Fax: (00 1) 5084572134

E-mail: mfujiwara@whoi.edu

James Hain

Associate Scientists at Woods Hole

Woods Hole, MA

USA

Tel: (00 1) 5085644449

Fax: (00 1) 5085401412

E-mail: jhain@earthlink.net

Philip Hamilton

New England Aquarium

Central Wharf

Boston, MA 02110

USA

Tel: (00 1) 6179735253

Fax: (00 1) 6177239705

E-mail: phamiltn@neaq.org

Phil Hammond

Sea Mammal Research Unit

Gatty Marine Laboratory

University of St. Andrews

St. Andrew's

Fife

KY16 8LB

UK

Tel: (01334) 462630

Fax: (01334) 462632

E-mail: p.hammond@smru.st-andrews.ac.uk

Bob Kenney

Box 41 - URI Oceanography

Narragansett, RI 02882

USA

Tel: (00 1) 4018746664

Fax: (00 1) 4018746497

E-mail: rkenney@gso.uri.edu
Amy Knowlton

Right Whale Research Project

New England Aquarium

Central Wharf

Boston, MA 02110-3309

USA

Tel: (00 1) 6179730210

Fax: (00 1) 6177239705

E-mail:aknowlton@neaq.org

Scott Kraus

New England Aquarium

Central Wharf

Boston, MA 02110

USA

Tel: (00 1) 6179735457

Fax: (00 1) 6177239705

E-mail:skraus@neaq.org

Jeff Laake

National Marine Mammal Laboratory

7600 Sand Point Way NE

Seattle, WA 98115

USA

Tel: (00 1) 2065264017

Fax: (00 1) 2065266615

E-mail: jeff.laake@noaa.gov

Marilyn Marx

Right Whale Research Project

New England Aquarium

Central Wharf

Boston, MA 02110

USA

Tel: (00 1) 6179736584

Fax: (00 1) 6177239705

E-mail:mmarx@neaq.org

Charles 'Stormy' Mayo

Center for Coastal Studies

59 Commercial Street

P.O. Box 1036

Provincetown, MA 02657

USA

Tel: (00 1) 5084873622

Fax: (00 1) 5084874495

E-mail: stormym33@pobox.com

Jim McMillan

Science Branch

Fisheries and Oceans Canada

Bedford Institute of Oceanography

Dartmouth

Nova Scotia

B2Y 4A2

CANADA

Tel: (00 1) 9024263516

Fax: (00 1) 9024261506

E-mail: mcmillanj@mar.dfo-mpo.gc.ca 
Michael Moore

Mailstop 33

Biology Department Redfield 244

Woods Hole Oceanographic Institution

Woods Hole, MA 02543

USA

Tel: (00 1) 5082893228

Fax: (00 1) 5084572134

E-mail:mmoore@whoi.edu

Richard Pace

Northeast Fisheries Science Center

166 Water Street

Woods Hole, MA 02543

USA

Tel: (00 1) 5084952253

Fax: (00 1) 5084952066

E-mail: rpace@whsun1.wh.whoi.edu

Victoria Portway

Smithsonian Institution

Washington, DC 20560-0315

USA

Tel: (00 1) 2026339895

Fax: (00 1) 2027862566

E-mail:vportway@ceps.nasm.edu

Howard Rosenbaum

Molecular Systematics Laboratory

American Museum of Natural History

$79^{\text {th }}$ Street and Central Park West

New York, NY 10024

USA

Tel: (00 1) 2127695942

Fax: (00 1) 2127695277

E-mail: hcr@amnh.org
Steve Swartz

NOAA Fisheries

Southeast Fisheries Science Center

75 Virginia Beach Drive

Miami, FL 33149

USA

Tel: (00 1) 3053614487

Fax: (00 1) 3053614478

E-mail: steven.swartz@noaa.gov

Barbara Taylor

Southwest Fisheries Science Center

PO Box 271

La Jolla, CA 92038

USA

Tel: (00 1) 8585467178

Fax: (00 1) 8585467003

E-mail: taylor@caliban.ucsd.edu

Paul Wade

Alaska Fisheries Science Center

7600 Sand Point Way NE

Seattle, WA 98115-0070

USA

Tel: (00 1) 2065264539

Fax: (00 1)206 5266615

E-mail: paul.wade@noaa.gov

Brad White

McMaster University

1280 Main Street W.

Hamilton, Ontario

L8S 4K1

CANADA

Tel: (00 1) 9055259140

Fax: (00 1) 9055226066

E-mail:whitebn@mcmaster.ca 


\section{Annex B Agenda}

1. Introductory items

2. Agenda

3. Review of documents

4. Review of available data 4.1 Recommendations

5. Review of available models

6. Overview of existing knowledge of population parameters

6.1 Stock and sub-stock structure

6.1.1 Recommendations (and see Item 8)

6.2 Population size

6.3 Age composition

6.4 Reproduction

6.5 Survivorship

6.6 Conclusion
7. Assessment of status and trends

7.1 Results from population modelling 7.1.2 Recommendations

7.2 Results from population monitoring

7.3 Factors affecting trends

7.3.1 Direct anthropogenic interactions

$$
\text { 7.3.1.1 Recommendations }
$$

7.3.2 Habitat degradation

7.3.2.1 Recommendations

7.3.3 Population structure and recruitment

7.3.4 Inbreeding

7.4 Comparison with other populations

8. Conclusion and recommendations

8.1 Research

8.1.1 General

8.1.2 Highest priority

8.2 Management

9. Other business 


\section{Annex C List of Documents}

\section{SC/099/RW}

1. Cooke, J. and Glinka, S. A comparative analysis of the demography of the Southwest Atlantic and Northwest Atlantic right whale populations from photo-identification of calving females.

2. Wade, P.R. and Clapham, P.J. The influence of sighting probabilities on survival estimates for North Atlantic right whales.

3. Hain, J.H.W., Kenney, R.D., Knowlton, A.R. and Kraus, S.D. Heterogeneity, sampling, presumed mortality, and the estimation of population parameters for the North Atlantic right whale.

4. Miller, C. and Moore, M. Blubber thickness in Atlantic E. glacialis and E. australis.

5. Brault, S. and Caswell, H. Draft report of the first Woods Hole workshop on right whale demography.

6. White, B.N., Waldick, R., Tomlinson, C., Malik, S., Brown, M., Hamilton, P., Knowlton, A., Slay, C. and Kraus, S. The status of the North Atlantic right whale as determined from genetic data.

7. Fujiwara, M., Brault, S. and Caswell, $H$. Stage-structured demographic analysis of the North Atlantic right whale.

\section{For Information Papers}

1. Hain, J.H.W., Ellis, S.L., Kenney, R.D. and Slay, C.K. 1999. Sightability of right whales in coastal waters of the United States with implications for the aerial monitoring program. pp.191-207 In: Marine Mammal Survey and Assessment Methods. A.A. Balkema, Rotterdam.

2. Rosenbaum, H.C., Egan, M.G., Clapham, P.J., Brownell, R.L. Jr., Malik, S., Brown, M., White, B.N., Walsh, P. and DeSalle, R. 2000. World-wide genetic differentiation of Eubalaena: questioning the number of right whales species. Mol. Ecol. 9(11):1793-1802.

3. Best, P.B., Brandão, A. and Butterworth, D.S. 2001. Demographic parameters of southern right whales off South Africa. [Published in this volume].
4. Portway, V., Best, P.B., Clapham, P.J., Hamilton, P.K., Moore, M.J., Payne, R., Rowntree, V., Rivarola, M. and Schaeff, C.M. 2000. Mitochondrial DNA differentiation between two wintering populations of southern right whales (Eubalaena australis) off South Africa and Peninsula Valdes, Argentina. Mar. Ecol. Progress Ser. (In press).

5. Weinrich, M.T., Kenney, R.D. and Hamilton, P.K. 2000. Right whales (Eubalaena glacialis) on Jeffreys Ledge: an unrecognized habitat? Mar. Mammal Sci. 16 (In press).

6. Waldick, R.C., Brown, M.W. and White, B.N. 1999. Characterization and isolation of microsatellite loci from the endangered North Atlantic right whale. Mol. Ecol. (In press).

7. Malik, S., Brown, M.W., Kraus, S.D., Knowlton, A.R., Hamilton, P.K. and White, B.N. 1999. Assessment of mitochondrial DNA structuring and nursery use in the North Atlantic right whale (Eubalaena glacialis). Can. J. Zool. 77: 1-6.

8. Malik, S., Brown, M.W., Kraus, S.D. and White, B.N. 2000. Analysis of mitochondrial DNA diversity within and between North and South Atlantic right whales. Mar. Mammal Sci. 16 (In press).

9. Knowlton, A.R. and Kraus, S.D. 2001. Mortality and serious injury of northern right whales (Eubalaena glacialis) in the western North Atlantic Ocean. [Published in this volume].

10. Kraus, S.D., Knowlton, A.R., Hamilton, P.K., Deney, R.D. and Slay, C.K. In review. Status and trends in reproduction in North Atlantic right whales. J. Cetacean Res. Manage. [See Kraus et al., this volume.]

11. Moore, M.J., Miller, C.A., Weisbrod, A.V., Shea, D., Hamilton, P.K., Kraus, S.D., Rowntree, V.J., Patenaude, N. and Stegeman, J.J. 1998. Cytochrome P450 1A and chemical contaminants in dermal biopsies of northern and southern right whales. [SC/M98/RW24].

12. IWC. 1999. Extract from SC/51/4, Report of the Scientific Committee.

13. IWC. 1998. Extracts from the Cape Town meeting report. 


\section{Annex D \\ Working Group on Heterogeneity in Sighting Probability}

Members: Burnell, Donovan, Friday, Hamilton, Knowlton, Laake (Convenor), Marx, McMillan, Pace.

\section{TERMS OF REFERENCE}

(1) Identify factors of the photo-identification sampling and matching process that may introduce heterogeneity in sighting probability.

(2) Identify existing data (covariates) that may be used to reduce/model heterogeneity in sighting probability.

(3) Develop strategy for explaining/modelling heterogeneity in existing and future photo-identification data collection.

2. IDENTIFY FACTORS OF THE PHOTOIDENTIFICATION SAMPLING AND MATCHING PROCESS THAT MAY INTRODUCE HETEROGENEITY IN SIGHTING PROBABILITY

Sighting probability through photo-identification is affected by the chances of encountering whales, selection of whales to be photographed, obtaining adequate photographs, and matching to the existing catalogue. Variation in these processes can introduce heterogeneity in sighting probability that primarily biases estimates of population size and to a lesser degree, estimates of survival rate (Hammond et al., 1990). The Working Group identified the following potential sources of heterogeneity in sighting probability within each of the aspects of the photo-identification process given below.

I. Whale encounter probability depends on:

(a) spatial and temporal (within and between year) distribution of whales relative to the spatial and temporal distribution of sampling; and

(b) ability to sight whales which depends on the survey platform, observer ability, whale diving behaviour, group size and a variety of other factors that affect sightability.

II. Selection of whales to photograph depends on:

(a) group size of the whales (e.g. large groups may be selected more often); and

(b) survey platform and logistics of sampling the survey region (e.g. aerial surveys in offshore regions are less likely to sample individual whales).
III. Obtaining adequate photographs of a whale in a single encounter depends on:

(a) whale behaviour, which may vary for the following reasons:

(1) behavioural response to the survey platform (e.g. diving as an aversive response to a circling aircraft, or avoiding a motorised boat);

(2) predominant whale activity (e.g. social or skim feeding) as it affects the display of head, tail, lip callosities, etc.;

(3) individual variation in behaviour; and

(4) group size.

(b) researcher experience;

(c) time spent with the whale(s) and number of photographs taken;

(d) various factors that may affect photo quality such as approach distance, weather, lighting, etc.;

(e) survey platform, which may limit the amount of time available to spend with a whale;

(f) group size, which affects the number of photographs obtained per whale and the ability to link different photos of the same whale.

IV. Successful matching to the existing catalogue or adding a newly identified whale depends on:

(a) features of the photos obtained during the encounter:

(1) photo quality (e.g. contrast, image size, sharpness);

(2) number of different aspects (e.g. head, back, tail, etc.) photographed; and

(3) distinctiveness of the whale (e.g. amount and shape of scars, pigment discoloration, callosities and their distribution across the body, uniqueness of the callosity pattern broken versus continuous). Temporary characteristics such as skin sloughing, cyamids, and callosity topography are used for matching within season but they are not useful for between-year matches.

(b) the same features of the existing whale photographs in the catalogue at the time the new set of photographs are matched, which depends on the number of previous sightings of the whale;

(c) experience of the individual matching the photographs which may interact with the quality of the photograph. For the right whale catalogue, more than one experienced matcher examines all matches and non-matches of photographic events. However, proposed matches are given higher priority to avoid 
false positives and whilst non-matches are reviewed they are done so with a lower priority. This creates a time lag in adding new whales.

\section{IDENTIFY EXISTING DATA (COVARIATES) THAT MAY BE USED TO REDUCE/MODEL HETEROGENEITY IN SIGHTING PROBABILITY}

The Working Group recognised that some of the features such as sex, age or stage, and spatial/temporal distribution patterns used in the analyses of SC/O99/RW2 and SC/O99/RW7 should be useful variables to model variability in encounter probability and as proxies for various behavioural differences that affect success in obtaining photographs. The Working Group also recognised that there were limits to modelling heterogeneity and that some factors may not be easily quantified.

Typically, annual sighting histories of whales have been constructed based on the composite result of all sampling throughout the year in all regions. The composite nature of the sampling should reduce the effects of heterogeneity somewhat by increasing overall sighting probability. However, the composite sampling complicates the identification and definition of covariates for most aspects involving sampling (I, II) and photography (III). For example, an effort measurement is difficult to define for the composite sampling of whalewatching boats and dedicated vessel and aircraft surveys. Likewise, in general it will be difficult to define covariates for any factor related to individual photographic events. The Working Group considered such measures as the number of photographs taken but noted that these types of measures do not always adequately reflect matchability (e.g. experienced researchers will often take very few photos of a very distinctive whale) and they are inappropriate because they are the result of sighting and not a predictor of sighting success.

The primary determinant of matching success is the distinctiveness of the whale and the type and quality of the photographs in the catalogue. Some caution is necessary in defining variables such that they are not influenced by the accumulation of photographs over years; otherwise, bias may be introduced because more photographs will be collected from survivors. If matches were only made in a year with the photographs available prior to that year, then the quality, distinctiveness, and number of photographs available in the catalogue at that time could be used as a predictor for that year. As the number and quality improved over time, the value of the predictor for ensuing years would change. This approach requires documentation of these features through time - this does not currently exist. In addition, matches in the existing sighting histories have been determined backwards in time (i.e. using photographs from year $t$ to establish a match in year $t-x$ ), so the matching probability of previous years depends on future years which can only occur for survivors. The current database does have a defined field for quality of the photos in the catalogue but it has not been updated to include more recent photographs and its definition did not distinguish adequately between distinctiveness of marking and photo quality.

Matches of photographs taken from aerial and vessel surveys are often difficult to match. An easily constructed and possibly important covariate may be the source of existing photographs in the catalogue (i.e. vessel, aerial, or aerial and vessel). This covariate will not require a re-evaluation of photographs but does need to be reconstructed through time.

\section{DEVELOP STRATEGY FOR EXPLAINING/ MODELLING HETEROGENEITY IN EXISTING AND FUTURE PHOTO-IDENTIFICATION DATA COLLECTION}

Heterogeneity in sighting probability has been identified through goodness-of-fit tests (SC/O99/RW5) for time dependent models. The Working Group proposes that similar tests be conducted for models that incorporate sex, stage, and spatial covariates as appropriate to determine if additional heterogeneity remains. If those covariates do not remove all of the heterogeneity, further consideration should be given to devising covariates that would describe whale distinctiveness and photographic quality through time. The Working Group recommends that the quality and distinctiveness codes identified during the Cape Town Workshop should be used for the existing catalogue and carried forward in time in the database with documentation of matching.

\section{REFERENCE}

Hammond, P.S., Mizroch, S.A. and Donovan, G.P. (eds.). 1990. Individual Recognition of Cetaceans: Use of Photo-Identification and Other Techniques to Estimate Population Parameters. International Whaling Commission, Cambridge, UK. [vi]+440pp. 


\section{Annex E Proposal for a Workshop on Right Whale Genetics}

\section{RATIONALE}

Preliminary analyses indicate that the understanding of right whale dynamics can be significantly improved through consideration of genetic data. Demographic models indicate that calving intervals have increased, that survival rates of certain components of the population have decreased (particularly among reproductively active females) and that survival rates differ for groups of whales utilising different areas. Genetic data indicate that there is female philopatry to different feeding areas that is passed on to calves that results in significantly different genetic profiles in different areas. Some possible uses of genetic data are: to delineate groups exposed to different levels and types of risks, to estimate the level of female and male dispersal between different areas, to estimate the magnitude of whales that may never be available for photographic sampling by examination of paternity (identification of missing fathers), to identify the plausibility of more than one calving ground and multiple breeding grounds, the relative plausibility that current genetic patterns could have resulted from a bottleneck, a population that has remained rare for a long period or a population that has been recently reduced, and to assess the plausibility of reduced long-term fitness.

Future models are urgently needed to identify the source of increased risk. Model results could be used to eliminate risk hypotheses, strengthen conclusions about status and trends, prioritise research and guide management decisions. Although genetic data can play an essential role in such management models, the use of genetic data to estimate demographic parameters and evaluate risk hypotheses is novel. As demonstrated by the demographic analyses already completed the understanding of data can be most quickly accomplished through numerous researchers approaching the problem.

\section{TERMS OF REFERENCE}

The following draft terms of reference are proposed:

(1) explore a range of population genetic analytical techniques;

(2) develop new analytical techniques to estimate model parameters specific of right whale conservation models; and

(3) identify the best approaches for both future genetic research both in terms of needed sampling, potential additional markers and development of future analytical techniques.

\section{STEERING GROUP}

Taylor (Convenor), Brault, Brownell, Clapham, Donovan, Rosenbaum, White.

\section{DATES AND VENUE}

White indicated that the outstanding genetic analyses should be completed in one year. It is proposed that the Workshop be held in New England after the 2000 meeting of the Right Whale Consortium in order to reduce travel expenses. 


\section{Annex F \\ Estimates of Current Abundance}

Table 1 shows estimates of recent (1995-96) population size obtained by various methods. The method of calculation for each count or estimate is given below. Catalogued animals known to have been alive in 1996 provide a firm lower bound of 263 for total abundance in that year. The statistical approaches (Caswell et al., 1999; SC/O99/RW2) are sensitive to violations of their assumptions when used to provide abundance estimates, and are expected to provide negatively biased estimates because of heterogeneity in sightings probabilities by area. It is therefore not surprising that the 'best' estimates produced by these methods are less than the lower bound of 263. The high estimated sighting probabilities from these methods do, however, suggest that the overall abundance in 1996 is unlikely to have been much greater than the 263 lower bound.

A lower bound on the reproductive female component is provided by the 58 animals known to have calved by 1996 who are also known to have been alive in 1996 (i.e. seen in 1996 or both before and after 1996). For the same reasons, the true number is considered unlikely to be much in excess of this.

The statistical analyses to date have concentrated primarily on the estimation of survival and sighting probability. Further research is required before definitive recommendations can be offered as to the best approach to estimate abundance from the photo-id data.

\section{1. $n / p$ MARK-RECAPTURE METHOD FROM CASWELL ET $A L$. (1999) [CASWELL AND FUJIWARA]}

The Cormack-Jolly-Seber model used by Caswell et al. (1999) produces estimates of sighting probability $p(t)$ as a function of time (year). We also computed $95 \%$ profile

Table 1

Summary of population counts/estimates from photo-identilication data.

\begin{tabular}{lllcccc}
\hline Method & Component & Year & Count & Estimate & (95\% CL) & Relerence \\
\hline Catalogued, known to be alive & Total & 1996 & 263 & & & \\
Catalogued, presumed alive & Total & 1996 & 296 & & & \\
As above + suspected missed & Total & 1996 & 314 & & & \\
& & & & 230 & $(220-242)$ & Caswell et al. 1999 \\
Cormack-Jolly-Seber & Total & 1995 & & 250 & $(194-321)$ & SC/O99/RW2 \\
$n / p$ by cluster & Total & 1996 & & & \\
Catalogued, known to be alive & Calving female & 1996 & 58 & & & SC/O99/RW1 \\
Catalogued, presumed alive & Calving lemale & 1996 & 70 & & & \\
Southern right model & Calving lemale & 1996 & & 57 & (52-98) &
\end{tabular}

(a) Minimum population estimates based on annual counts (1990-1997)

\begin{tabular}{lccc}
\hline Year & No. seen in year + No. seen in years before and after & Year & No. seen in year + No. seen in years before and after \\
\hline $1997^{*}$ & $248(230+18)$ & 1993 & $253(177+76)$ \\
1996 & $263(216+47)$ & 1992 & $252(130+122)$ \\
1995 & $258(216+42)$ & 1991 & $249(158+91)$ \\
1994 & $259(206+53)$ & 1990 & $250(148+102)$ \\
\hline
\end{tabular}

*This estimate is likely biased downward because of limited post 1997 data.

\begin{tabular}{lr} 
(b) Abundance as of December 1996 & 374 \\
\hline No. in catalogue & -5 \\
Animals seen only prior to 1979 & -9 \\
Mortalities of identilied whales & -4 \\
Whales mortally injured & +13 \\
$1995 / 96$ calves not catalogued & 369 \\
Subtotal & -5 \\
Presumed mortality 1979-1993 & -38 \\
Presumed mortality 1994-1996 & $\mathbf{2 9 6}$ \\
'Mid' estimate & +18 \\
Conservative correction for unlikely presumed mortality (based on individuals with 'ollshore signature') & $\mathbf{3 1 4}$ \\
'Best' estimate & \\
\hline
\end{tabular}


likelihood confidence limits (pointwise) on $p(t)$. Assuming that all whales have identical sighting probabilities, and that the probability of first sighting is the same as the probability of re-sighting, we estimated total population size as:

$$
\hat{N}(t)=\frac{n_{\mathrm{obs}}(t)}{\hat{p}(t)}
$$

where $n_{\mathrm{obs}}(t)$ is the number of whales observed in year $t$. An approximate standard error of $\hat{N}(t)$ is:

$$
\operatorname{SE}(\hat{N}(t))=\frac{n_{\mathrm{obs}}}{\hat{p}(t)^{2}} \mathrm{SE}(\hat{\mathrm{p}}(\mathrm{t}))
$$

We approximated $\mathrm{SE}(p)$ as $1 / 4$ of the width of the $95 \%$ profile likelihood interval.

The resulting estimates are shown in Fig. 1. The estimates agree closely with the projected trend in fig. 7 of Caswell et al. (1999), when that trend is conditional on beginning at $\hat{N}(1980)$.

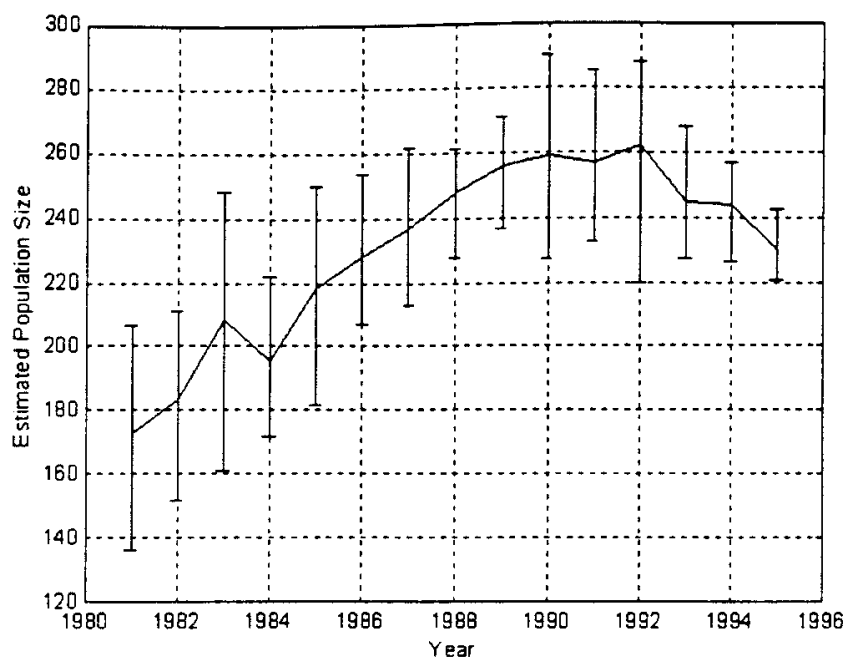

Fig. 1 Population estimates and 95\% CL by year from Caswell et al. (1999).

The assumptions required to make this estimate are very strong. Such estimates are generally considered to be more sensitive to violation of mark-recapture assumptions than are estimates of survival or transition rates.

\section{POPULATION ESTIMATES FROM THE WADE-CLAPHAM MODEL (WADE)}

\section{$2.1 n / p$ mark re-capture method}

Abundance can be estimated by taking the number of captured animals $(n)$ and correcting it by the inverse of the probability of capture $(1 / p)$. To use estimated capture probabilities from Wade and Clapham (SC/O99/RW2), this must be done for each group and then summed across groups. For 1996, the number of captures for clusters 1-4 were $32,9,84$, and 80 (total of 205), with estimated capture probability in 1996 of $0.930,0.328,0.900,0.850$. The estimated population size was therefore $249.8(95 \%$ CI 194.3, 321.3). The lower confidence limit is less than the number of identified individuals in 1996 (205), so this method does no better in providing a lower bound than simply using that number. This method can be negatively biased by individual heterogeneity in sighting probability.

\subsection{Correction for whales not seen 1991-96}

293 individual whales were identified in the years 1991-1996. This does not account for whales that may not have been seen in those years. Estimated capture probabilities from Wade and Clapham (SC/O99/RW2) can be used to make this correction. The probability of not being seen for those 6 years is the product of one minus the capture probability in each year. This probability (taking the weighted average across groups) is 0.0057 . One minus that quantity is the probability of being seen in any of those years (0.9943). One over this probability becomes the correction: $1.0058 * 293=294.7$. This method does not take account of whales seen within the years 1991-1995 that might have died by the year 1996 .

\section{POPULATION ESTIMATES USING THE SOUTHERN RIGHT WHALE MODEL (COOKE)}

This model estimates the size of the breeding female population (females who have had at least once calf in their lifetime) along with survival and calving rates as described in SC/O99/RW1. Since the model does not use sightings of animals in years when they do not calve, it is possible for the point estimate to be less than the minimum number of animals known (on the basis of the full data set) to be alive. The estimates are liable to be biased low through unaccounted-for heterogeneity.

\section{DIRECT COUNTING METHODS FROM THE CATALOGUE (KNOWLTON)}

The back-counting method defined by Knowlton et al. (1994) combined with criteria defined in Hain et al. (SC/O99/RW3) to estimate presumed mortality in years when survey effort was limited or stopped in offshore areas was carried out to provide a maximum and mid population estimate for 1996. A minimum population for 1996 was estimated by counting the number of animals seen in 1996 plus the number not seen in 1996 but seen both before 1996 and after 1996. The latter provides the minimum number definitely known to have been alive in 1996.

\subsection{6 estimates}

'Best' estimate - 314: total catalogued animals minus presumed dead (1979-1996), mortalities of known animals, and mortally injured known animals; plus calves born in 1995/1996 (not yet catalogued) and unlikely presumed mortalities (1994-1996) based on individuals with an 'offshore signature'.

'Standard' estimate - 296: total catalogued total catalogued animals minus presumed dead (1979-1996), mortalities of known animals, and mortally injured known animals; plus calves born in 1995/1996 (not yet catalogued).

'Minimum estimate' - 263: number of animals photographed in 1996 plus the number of animals photographed both before and after 1996 and not in 1996.

\subsection{Potential biases}

The 314 estimate is biased down if our correction for presumed mortalities is too conservative, and up if it is not conservative enough. The accuracy of this correction factor may be tested in the future as offshore surveys are resumed and the need to utilise it at all may be eliminated if offshore surveys are maintained and expanded. 
The 296 estimate may be biased upwards by dead animals that are unreported and/or animals that have died but have not yet become presumed dead; downwards if presumed dead criteria are violated.

The 263 estimate is a hard minimum and is likely biased downward from the best estimate because of the limited time frame after 1996 to resight animals seen prior to 1996 . Also the lack of effort in the offshore areas during the 1990s would reduce the chance of animals first sighted in the 1980s, when survey effort was high, to be resighted after 1996.
Each of these estimates are biased down by animals that exist but are not catalogued.

\section{REFERENCES}

Caswell, H., Fujiwara, M. and Brault, S. 1999. Declining survival probability threatens the North Atlantic right whale. Proc. Natl Acad. Sci. USA 96:3308-13.

Knowlton, A.R., Kraus, S.D. and Kenney, R.D. 1994. Reproduction in North Atlantic right whales (Eubalaena glacialis). Can. J. Zool. 72(7):1297-305. 